Article

\title{
Comparison of Historical Water Temperature Measurements with Landsat Analysis Ready Data Provisional Surface Temperature Estimates for the Yukon River in Alaska
}

\author{
Carson A. Baughman * and Jeffrey S. Conaway \\ U.S. Geological Survey Alaska Science Center, Anchorage, AK 99508, USA; jconaway@usgs.gov \\ * Correspondence: cbaughman@usgs.gov
}

Citation: Baughman, C.A.; Conaway, J.S. Comparison of Historical Water Temperature Measurements with Landsat Analysis Ready Data Provisional Surface Temperature Estimates for the Yukon River in Alaska. Remote Sens. 2021, 13, 2394. https://doi.org/10.3390/rs13122394

Academic Editor: Vincenzo Levizzani

Received: 24 May 2021

Accepted: 8 June 2021

Published: 19 June 2021

Publisher's Note: MDPI stays neutral with regard to jurisdictional claims in published maps and institutional affiliations.

Copyright: (C) 2021 by the authors. Licensee MDPI, Basel, Switzerland. This article is an open access article distributed under the terms and conditions of the Creative Commons Attribution (CC BY) license (https:/ / creativecommons.org/licenses/by/ $4.0 /)$.

\begin{abstract}
Water temperature is a key element of freshwater ecological systems and a critical element within natural resource monitoring programs. In the absence of in situ measurements, remote sensing platforms can indirectly measure water temperature over time and space. The Earth Resources Observation and Science (EROS) Center has processed archived Landsat imagery into analysis ready data (ARD), including Level-2 Provisional Surface Temperature (pST) estimates derived from the Landsat 4-5 Thematic Mapper (TM), Landsat 7 Enhanced Thematic Mapper Plus (ETM+), and Landsat 8 Thermal Infrared Sensor (TIRS). We compared in situ measurements of water temperature within the Yukon River in Alaska with 52 instances of pST estimates between June 2014 and September 2020. Agreement was good with an RMSE of $2.25^{\circ} \mathrm{C}$ and only a slight negative bias in the estimated mean daily water temperature of $-0.47^{\circ} \mathrm{C}$. For the 52 dates compared, the average daily water temperature measured by the USGS streamgage was $11.3^{\circ} \mathrm{C}$ with a standard deviation of $5.7^{\circ} \mathrm{C}$. The average daily pST estimate was $10.8^{\circ} \mathrm{C}$ with a standard deviation of $6.1^{\circ} \mathrm{C}$. At least in the case of large unstratified rivers in Alaska, ARD pST can be used to infer water temperature in the absence of or in tandem with ground-based water temperature monitoring campaigns.
\end{abstract}

Keywords: Landsat; analysis ready data; river; water temperature; Alaska

\section{Introduction}

Water temperature is one of the key elements of freshwater ecological systems [1,2]. In Arctic and sub-Arctic rivers, water temperature especially relates to the physical and thermal features of a river, as it affects how rivers interact with terrestrial portions of the landscape and governing river biotic communities [3]. Water temperature influences the rate of thermal erosion in permafrost-rich landscapes [4], and it controls the timing and extent of in-stream ice formation, which leads to mechanical erosion and seasonal flooding during spring break-up [5]. Water temperature affects the timing and composition of the stream biotic community, influencing productivity [6] and habitat quantity and quality [7]. Water temperature plays a key role in the life cycle of salmonid species that are of significant ecological, cultural, and economic concern globally [8]; it can affect migration success, spawning location, incubation success, individual growth, competitive ability, and resistance to biotic and abiotic stresses including parasites, diseases, and pollutants $[9,10]$.

The fundamental importance of water temperature makes it a critical element within natural resources monitoring programs. The spatial and temporal resolutions of water temperature data are highly variable depending on water body characteristics, monetary and technological resources, and research needs. Extensive, high frequency systems can be found in Europe where, for example, the Swiss Federal Office for Water and Geology as well as the Wasser- und Energiewirtschaftsamt des Kantons Bern have maintained a record of water temperature collected every minute at over 90 locations across Switzerland since the 1960s [11]. For most hydrological systems, however, such systems are not or have not 
been in place. This is especially true for the remote, northern hydrological systems where installing and maintain monitoring systems is less feasible.

The U.S. Geological Survey (USGS) operates the largest streamgaging network in the U.S. with over 10,000 monitoring stations including 111 in Alaska. Water temperature is measured every $15 \mathrm{~min}$ at 1836 USGS stations including 63 in Alaska. Three streamgages are located on the Yukon River within three remote villages, i.e., Eagle, Stevens Village, and Pilot Station, respectively gaging the upper, middle, and lower reaches of the $\approx 2000 \mathrm{~km}$ of river within Alaska. Water temperature has only been continuously monitored at the Pilot Station streamgage for the summer in 1979 and then during the ice-free season between 1 May 2014 and 24 October 2020 [12]. Subsequently, like other large Arctic and sub-Arctic river systems, systematic and extensive water temperature data for the Yukon River are difficult to capture and are historically lacking $[13,14]$.

In the absence of in situ measurements, remote sensing platforms can indirectly measure water temperature over time and space [15]. Thermal infrared radiation (TIR) emitted from land and water surfaces can be measured by satellite, airborne, and groundbased sensors to provide indirect estimates of surface temperature [16-18]. In the case of water bodies, radiation is detected from only the top layer (upper $10 \mathrm{~cm}$ ) of the water [15]. For deep water bodies that are thermally stratified, the utility of water surface temperature becomes case-specific, but for large turbulent rivers such as the Yukon River where thermal stratification is minimal or nonexistent [19], water surface temperature becomes more representative of water temperature as a whole [15].

The Landsat satellite campaign, a joint effort between National Aeronautics and Space Administration (NASA) and the USGS, offers an unprecedented record of remotely sensed data concerning the earth's surface over the last five decades. Beginning in 1972, the family of Landsat satellites has been dedicated to remotely sensing the Earth's surface, providing useful data for applications including forestry, agriculture, geology, regional planning, education, and land use/land change research [20]. Since 1982, at least one Landsat satellite has been in operation while carrying sensors capable of measuring TIR emitted from land and water surfaces [20]. The suitable accuracy of Landsat-derived water temperature estimates has been established and demonstrated $[15,17,18]$, but previous studies are often temporally limited because they utilize only a small number of Landsat scenes $[18,21]$ due to the combination of limited ground truth data and the burdensome processing steps required to convert raw TIR data to kinetic water temperature.

In 2017, the Earth Resources Observation and Science (EROS) Center released archived Landsat imagery processed into analysis ready data (ARD) [22]. These data are rigorously processed and radiometrically calibrated across the succession of Landsat sensors for direct use in monitoring and assessing landscape change over time [23,24]. A primary goal of the Landsat ARD data is to provide remote sensing scientists with a common and consistent dataset that can be employed in time series analysis without taxing preprocessing steps [23-25]. ARD Landsat Level-2 Provisional Surface Temperature (pST) estimates are calculated using top of atmosphere (TOA) reflectance, top of atmosphere brightness temperature (TOA BT) bands derived from Landsat 4-5 Thematic Mapper (TM), Landsat 7 Enhanced Thematic Mapper Plus (ETM+), and Landsat 8 Thermal Infrared Sensor (TIRS) data [26]. Calculations also incorporate Advanced Spaceborne Thermal Emission and Reflection Radiometer (ASTER) Global Emissivity Database data and the ASTER Normalized Difference Vegetation Index (NDVI) [26]. Final pST estimates are generated using the single channel algorithm [24,27] with an atmospheric calibration methodology [25,28-30]. The Landsat pST product comprises nine acquisition-based rasters that include the temperature of the Earth's land and water surfaces in Kelvin, calculation inputs, and quality assessment information [26].

This study tests the agreement and accuracy of the Landsat ARD pST product when compared to in situ measurements for a portion of the lower Yukon River in Western Alaska. Our aim is not to model river water temperature but to assess the accuracy of the ARD pST estimates when utilized in a way intended by the ARD data developers, i.e., for 
inferring land surface conditions using preprocessed remotely sensed data for time series analysis. We assess the validity of the pST estimates at the 1, 10, and $100 \mathrm{~km}$ scales. We also assess the validity of inferring river water temperature at the USGS streamgage based on water temperature estimates from proximal and distal river segments, both upstream and downstream of the Pilot Station site. Test results can illuminate how practical it is for researchers or resource managers to utilize the Landsat ARD product for estimating river water temperature within the Yukon River when direct measurements have not been made in the past or cannot be made at present.

Remotely sensing water temperature in large Alaska rivers is a valuable tool for multiple reasons. Estimates can augment existing hydrologic monitoring systems such as the network of USGS streamgages. In the event streamgage data are disrupted due to technical or environmental factors, pST estimates could help fill data gaps. While streamgage data offer accurate point measurements, spatially explicit "heat maps" can depict the variation in water temperature due to river currents and cold- or warm-water contributions from tributaries, springs, groundwater, and hyporheic flow [15], which in turn is critical information for identifying thermal refugia for salmonid species [9]. Finally, historical estimates of water temperature can extend our record of measurement for large rivers and provide greater context for time series analysis in a region experiencing particularly rapid climate change [31].

\section{Study Area}

Our study focuses on a stretch of the Yukon River near the remote Alaskan village of Pilot Station (Figure 1). The Yukon is the largest river in Alaska and drains a 850,000 km² basin comprising 20 ecoregions [32]. The river is a transportation corridor across Alaska and an important migration route for salmon that are harvested commercially and for subsistence. Climate change is occurring at a faster rate in northern latitudes, and changes include permafrost thawing, glaciers melting, a reduction of time where the landscape is covered in snow, and plant communities shifting [33-35]. These changes impact the discharge and water quality of the Yukon River. The USGS monitors streamflow and water temperature continuously and collects discrete water quality samples near the mouth of the Yukon at the Pilot Station village. The USGS streamgage (15565447) is the longest record of water temperature collected by the USGS for the Yukon River (Figure 1).

Pilot Station and the broader landscape is adjacent to three prominent ecoregions, including the Yukon-Kuskokwim Delta to the south and west, the Nulato Hills to the north, and the Yukon River Lowlands to the east [36]. The climate ranges from moist polar to continental depending on elevation, the distance to the coast, and the sea-ice coverage of the Bering Sea [36]. Vegetation around Pilot Station and the Yukon River consists of highly productive stands of white spruce (Picea glauca (Moench) Voss), balsam poplar (Populus balsamifera spp.), and willow thickets (Salix sp.) [36]. The occurrence of tall trees is diminished as one moves down the river from Pilot Station and approaches the treeless, tundra-dominated landscape of the Yukon River Delta. Active floodplains and river bars support tall stands of alders and willows, while robust wet sedge meadows and aquatic vegetation dominate infilling sloughs and oxbow ponds [36].

At Pilot Station, the Yukon River occupies a single meandering channel approximately $820 \mathrm{~m}$ wide. Immediately upstream and downstream, as is common for the Yukon, the channel becomes broader and is intermittently divided by large islands. The mean annual discharge is $\approx 6430 \mathrm{~m}^{3} / \mathrm{s}$, with maximum discharge occurring in spring-summer due to peak snowmelt and glacier ablation [13,32]. During winter, discharge and suspended sediment drop to minima values, and the river freezes over. Historically, freeze-up occurs between late October and November while break-up occurs in May [5]. Each spring, following break-up, USGS personnel travel by plane to Pilot Station to configure and deploy the automated streamgage and sensor equipment. Readings are logged and transmitted via satellite throughout the summer. In early October, the equipment is removed before the 
river begins to freeze, otherwise the frozen river would damage the gaging equipment left in the water.

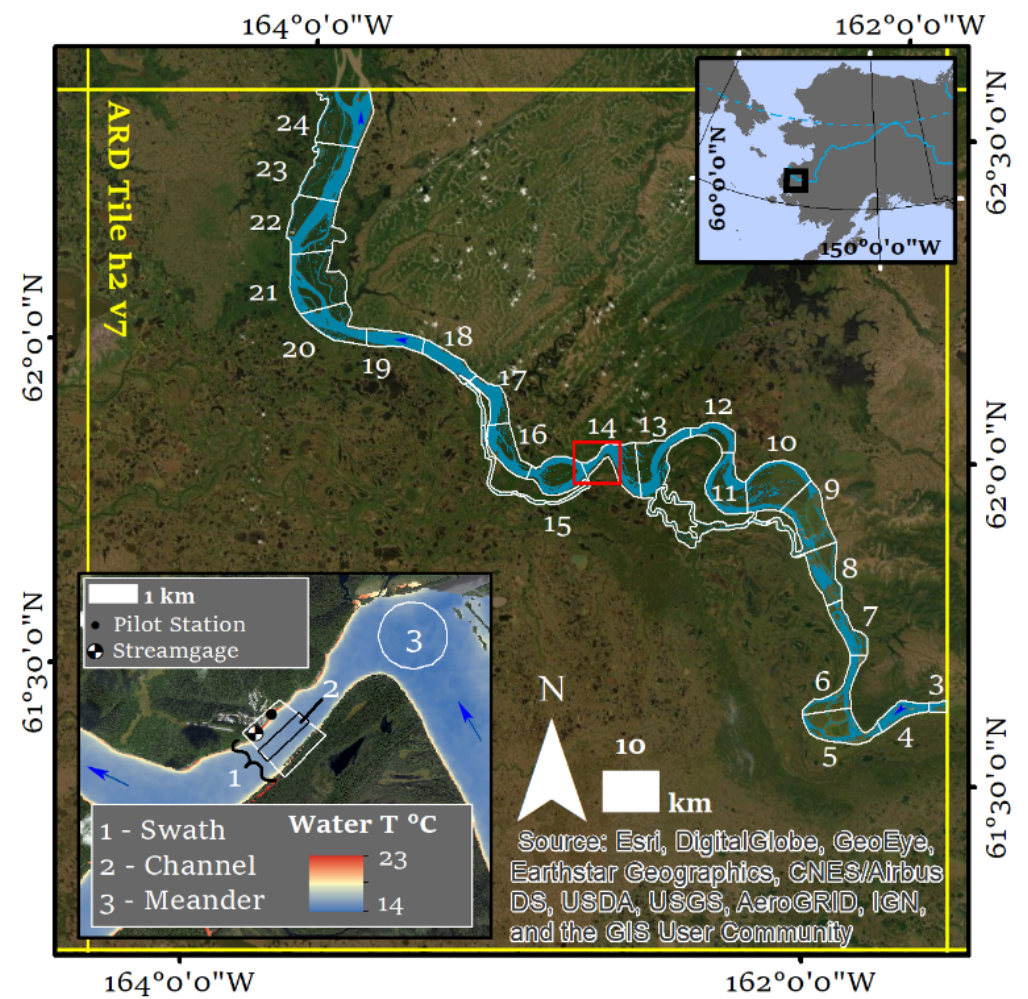

Figure 1. Study area showing location with respect to Alaska and the Yukon River (upper inset), distribution of river segments, and the extent of the Swath, Channel, and Meander AOIs with respect to the USGS streamgage located in Pilot Station (lower inset).

\section{Materials and Methods}

We compared water temperature records collected from the USGS streamgage with records estimated as part of the USGS-EROS Landsat ARD pST [24,26]. Daily mean water temperatures, summarized from 15 min intervals collected during the ice-free season between 1 May 2014 and 31 October 2020, were downloaded from the USGS site (https: / / waterdata.usgs.gov /, accessed on 15 November 2020) [12]. USGS personnel perform 7 temperature cross-section surveys annually to ensure that the point measurements at the streamgage are representative of the entire channel. Measurements across the channel and in the vertical profile typically vary less than \pm 0.5 degree at low to medium flows and \pm 0.8 degrees at higher flows. Landsat ARD pST scenes were downloaded in bulk from the EROS EarthExplorer website (https:/ / earthexplorer.usgs.gov/, accessed on 15 November 2020). Every pST package includes twelve output raster layers including surface temperature (ST), surface temperature quality assessment (STQA), atmospheric transmittance layer (ATRAN), emissivity layer (EMIS), emissivity standard deviation (EMSD), upwelled radiance layer (URAD), downwelled radiance layer (DRAD), thermal radiance layer (TRAD), distance to cloud (CDIST), pixel quality assessment (PIXELQA), radiometric saturation (RADSATQA), lineage index (LINEAGEQA), as well as an XML metadata file. We considered all scenes within the ARD tile that captures Pilot Station (horizontal 2, vertical 7) within the Alaska tile grid region and that were obtained between May and October for the years 2014-2020, i.e., the seasonal operation window of the USGS streamgage water temperature sensor. Scenes were filtered to exclude scenes with over $80 \%$ cloud or cloud shadow using controls within the EarthExplorer webpage.

We utilized three of the above rasters extensively in our study. The ST raster is simply the estimated surface temperature for every quality pixel within the scene. The derivation 
of these values is described in the introduction. Additionally, for every Landsat ARD scene, the PIXELQA raster assigns each pixel a condition (clear terrain, water terrain, cloud shadow, or snow/ice) based on spectral information. These conditions also include the confidence level (low, medium, and high) that a pixel is cloud-covered, with low confidence suggesting cloud-free and high confidence suggesting cloud-covered [24]. The "water, low confidence cloud" is pixel quality assessment bit value 68 (Landsat 4-7) or 324 (Landsat 8). We also employed the CDIST raster, which represents the distance (in kilometers) that a quality pixel is from the nearest cloud pixel [26].

Using a GIS [37], we excluded all surface temperature data except those related to water surfaces. We used ESRI's Reclassify tool and the PIXELQA output raster for each scene to create a clear-water mask. The Extract by Mask tool was then used with the newly derived clear-water mask to isolate pixel values from the ST and CDIST rasters, thereby creating cloud-free, water surface temperature, and distance to cloud rasters. These steps were iterated over every scene using the ModelBuilder function within ESRI's ArcGIS [37]. Zonal statistics were calculated from both rasters based on zones of interest (Figure 2).

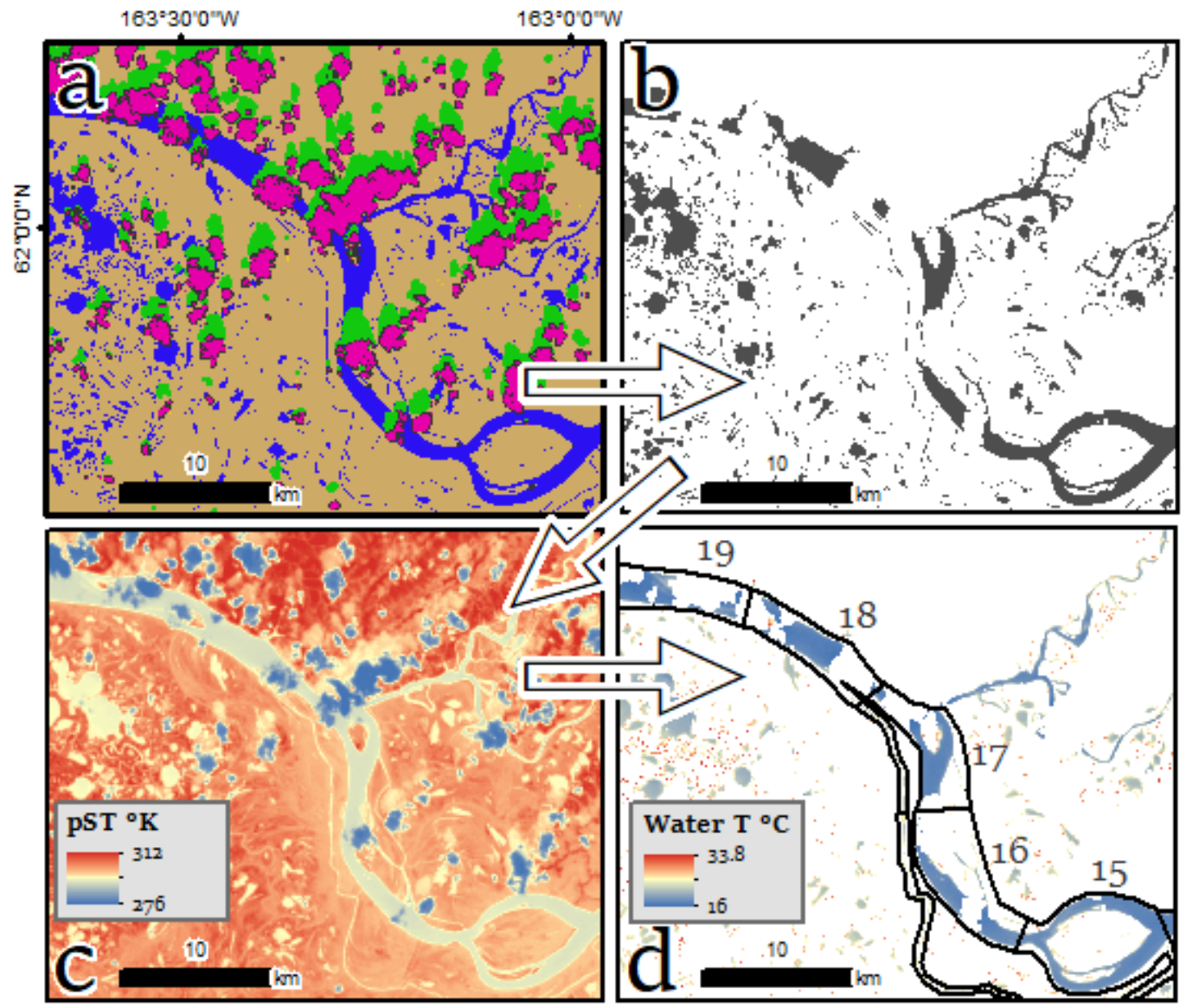

Figure 2. (a) PIXELQA raster qualifying land-low probability clouds (brown), water low probability clouds (blue), clouds (magenta), and cloud shadow (chartreuse). (b) Masking raster where water low probability cloud pixels are reclassified to a value of 1 and all else is null. (c) The surface temperature (ST) raster with blues depicting low temperatures surfaces and red depicting high temperatures. (d) ST raster after masking by water surface raster with zones of interest shown (black bounding lines).

Zonal statistics were first calculated for a $1 \mathrm{~km}$ long, $272 \mathrm{~m}$ wide, 30.5 hectare area of interest (AOI) of the Yukon river immediately adjacent to the USGS streamgage and occupying the middle of the main channel (Channel AOI). Extracting pST estimates from this AOI allows for the most direct comparison of in situ measurements and remotely sensed measurements. The single broad channel of the Yukon allows for sampling of quality pixels that are not 
influenced by shorelines, and it does not experience the emergence of islands or sandbars even during low water stages. Additionally, the water within the channel is historically well mixed and not prone to significant stratification. Routine measurements have found thermal stratification of the water column to vary by less than $1^{\circ} \mathrm{C}$.

Two additional AOIs in close proximity to the USGS streamgage were analyzed for potential variation in the accuracy of pST values introduced by river morphology and proximity. A roughly one kilometer by one kilometer, 120 hectare swath (Swath AOI) of river segment was designated to include the full width of the river, including warmer surface water estimates that occur along shorelines and are influenced by exposed shoreline material and adjacent vegetation [13]. Lastly, a circular AOI was delineated for a large meander upstream of the streamgage (Meander AOI). This zone was $1.3 \mathrm{~km}$ in diameter (132.7 hectare). The Meander AOI covered a greater area than the Channel or Swath AOI but still excludes shoreline features. Our intention was to sample water temperature estimates from a portion of the river that was physically close to the streamgage and Channel AOI but from a portion of the river that was morphometrically different (Figure 1).

The AOIs offer the most direct comparison between remotely sensed and in situ data but significantly limit the number of available Landsat scenes. Given that the Yukon is a very large, well-mixed, and unimpeded river, we assessed the validity of inferring at-streamgage temperature from more distant locations along the river, should they be the only available data in a given scene.

Zonal statistics were calculated for $n=21$ river segments within the ARD tile as well as for the river as a whole. The river within the ARD tile was divided into $10 \mathrm{~km}$ sections starting at the northern boundary of the ARD tile (the most downstream portion of the river) and includes twenty $10 \mathrm{~km}$ long segments and one $3 \mathrm{~km}$ river segment. The $10 \mathrm{~km}$ river segment length was subjectively chosen to provide an efficient resolution for exploring variation in agreement between remotely sensed and ground-based measurements. Statistics were based on a bounding shapefile that was manually digitized from ESRI's USA Topo Maps and the imagery basemaps in ArcMap to include all major channels and sloughs occupied by the Yukon River between 1985 and 2020 [37-39]. Large water bodies found on islands bordered by meandering sloughs were omitted by cutting and reshaping the shapefile.

The steps to derive zonal statistics for all AOIs and river segments were iterated for each ARD scene and compiled into zonal statistics summary tables with rows representing scene acquisition dates, columns representing zones of statistical interest (Segments or AOIs), and cell values representing estimated water temperature. A summary table was also compiled for the CDIST values. We included scene attributes for the summary table for the Channel AOI. All remotely sensed data were joined to the USGS streamgage data by date. This resulted in the final winnowing of some ARD data due to a lack of corresponding streamgage data. This was most common in early May and late October when streamgage measurements had yet to begin or had already ceased, respectively. There are also a number of mid-season data gaps in the USGS streamgage record due to equipment failures.

Agreement between remotely sensed pST and in situ streamgage measurements were tested using the Pearson's product-moment correlation (r). We reject the null hypothesis (no agreement) if $p$-values $<0.05$ and report the proportion of the variance $\left(\mathrm{r}^{2}\right)$ in the $\mathrm{pST}$ measurement that is dependent on true changes in water temperature as measured by in situ measurements. Accuracy was further validated using root mean square error (RMSE), the variance ratio (VR), and bias. Accuracy of the pST estimates can be assessed based on RMSE calculated as follows where $\left(\hat{\bar{y}}_{i}\right)$ is the estimated mean pST and $\left(\bar{y}_{i}\right)$ is the mean measured streamgage temperature on the $i$-th date, respectively:

$$
\operatorname{RMSE}=\sqrt{\frac{1}{n} \sum_{i=1}^{n}\left(\hat{\bar{y}}_{i}-\bar{y}_{i}\right)^{2}}
$$


The variance ratio is a measure of how similar the variance in values of estimated values is compared to the variance in the true values. It is derived as the ratio of the standard deviation of the pST estimates $\left(\hat{y}_{i}\right)$ and the measured streamgage temperatures $\left(y_{i}\right)$ :

$$
V R=S T D \hat{y} / S T D y
$$

We report the bias of the pST estimates, which is calculated as the difference between the mean pST estimates $(\hat{\bar{y}})$ and the mean measured streamgage temperatures $(\bar{y})$ :

$$
\text { Bias }=\hat{\bar{y}}-\bar{y}
$$

We tested the correlation $\left(\mathrm{r}^{2}, p\right.$-value $)$ of the residuals $\left(\hat{y}_{i}-y_{i}\right)$ with scene attributes that we believe could account for errors in pST estimates. River morphology and atmospheric conditions at the time of scene acquisition can influence the count, the standard deviation, and the variety of quality pixels within an AOI on a given date. We assessed whether accuracy was correlated with the month of acquisition to look for possible seasonal effects and with the year of acquisition to look for interannual variation. The proximity of clouds to the quality pixels can indicate the likelihood of cirrus or haze (which escapes automated cloud detection) contaminating estimates. Lastly, we compared the accuracy of pST estimates when produced from Landsat 7 and the ETM+ sensor versus the Landsat 8 and the TIRS sensor. We report the agreement and accuracy of the pST estimates compared to measured temperatures for all AOIs and segments within the study.

\section{Results}

\subsection{Provisional Surface Temperature Estimates at the $1 \mathrm{~km}$ Scale}

We downloaded 291 scenes from the EROS website for the months of May, June, July, August, September, and October between the year 2014 and 2020 that had less than 80\% cloud or cloud shadow. Landsat 8 (L8) acquired 152 scenes and Landsat 7 (L7) acquired 139 scenes. Some scenes did not contain quality pixels of the Yukon River itself. Of the 291 scenes, 278 had at least one pixel of clear water somewhere within the bounds of the Yukon River $(\mathrm{L} 8=142$, L7 = 136). Matching all Landsat scene acquisition dates with all possible USGS streamgage measurement dates yielded a final 209 Landsat scenes (L8 = 105, L7 = 104) with concurrent USGS streamgage measurements (Table A1). Every scene has a unique distribution of quality pixels that occur within the bounds of the Yukon River. As a result, not every river segment receives an identical number of surface temperature estimates. Scene coverage over the mid-channel zone permitted a sample size (n) of 52 dates for direct comparison between streamgage data and ARD estimates. The larger $1 \mathrm{~km}$ Swath AOI adjacent to the Pilot Station streamgage produced 53 dates while the upstream Meander AOI accrued 59 dates (Table 1).

Table 1. Summary of agreement between Swath, Channel, and Meander AOI and USGS streamgage data. RMSE is the root mean squared error. VR is the variance ratio.

\begin{tabular}{lcccccccc}
\hline Segment & $\mathbf{n}$ & $\hat{\bar{y}}\left({ }^{\circ} \mathbf{C}\right)$ & $\overline{\mathbf{y}}\left({ }^{\circ} \mathbf{C}\right)$ & $\operatorname{RMSE}\left({ }^{\circ} \mathbf{C}\right)$ & VR & Bias $\left({ }^{\circ} \mathbf{C}\right)$ & $\mathbf{r}^{2}$ & $p$-Value \\
\hline Swath & 53 & 11.61 & 11.36 & 2.39 & 1.02 & 0.25 & 0.84 & $1.0 \times 10^{-21}$ \\
\hline Channel & 52 & 10.81 & 11.28 & 2.25 & 1.07 & -0.47 & 0.87 & $1.8 \times 10^{-23}$ \\
\hline Meander & 59 & 11.76 & 11.98 & 2.52 & 1.00 & -0.22 & 0.78 & $1.7 \times 10^{-20}$ \\
\hline
\end{tabular}

Agreement between pST and streamgage data for the Channel AOI was very good with a Pearson's product-moment correlation of $r=0.931$ and an $r^{2}=0.87$ (Table 1 ). With a $p$-value $<<0.01$, we reject the null hypothesis of no correlation and accept the alternate hypothesis that true correlation exists. Nearly $90 \%$ of the variation in the estimated pST is explained by the true variation in water temperature as measured by the USGS streamgage. Within the study period, the average daily water temperature as measured by the USGS 
streamgage was $11.28{ }^{\circ} \mathrm{C}$ with a standard deviation of $5.70{ }^{\circ} \mathrm{C}$. The average daily pST as estimated for the Channel AOI was $10.81^{\circ} \mathrm{C}$ with a standard deviation of $6.07^{\circ} \mathrm{C}$. The average daily bias between in situ and remotely sensed daily water temperatures (difference $=$ remotely sensed - in situ) was $-0.47^{\circ} \mathrm{C}$ with an RMSE of $2.25^{\circ} \mathrm{C}$ and a VR of 1.07 .

A singular date within our study period captured all three temperature acquisition methods. On 22 August 2019, USGS personnel completed a manual temperature crosssection survey in conjunction with the automated streamgage that was in operation and was recording data. Simultaneously, Landsat 7 acquired cloud-free surface reflectance around Pilot Station. The three data streams demonstrate good agreement (Figure 3). The manual temperature cross section recoded a consistent $\approx 15{ }^{\circ} \mathrm{C}$ between $10: 30$ am and 11:15 am AKST (Figure 3a). The automated streamgage recorded temperatures fluctuating between $14.9{ }^{\circ} \mathrm{C}$ and $15.0{ }^{\circ} \mathrm{C}$ throughout the same period of time (Figure $3 \mathrm{~b}$ ). Between 12:49 pm and 12:50 pm Alaska Standard Time, Landsat 7 acquired data within path 77, row 17, which ultimately provided the reflectance data for the pST estimates. Provisional surface temperature estimates were available for 221 pixels that fell within the Channel AOI with an average value of $14.5^{\circ} \mathrm{C}$ and a standard deviation of $3.4{ }^{\circ} \mathrm{C}$ (Figure $3 \mathrm{c}$ ).

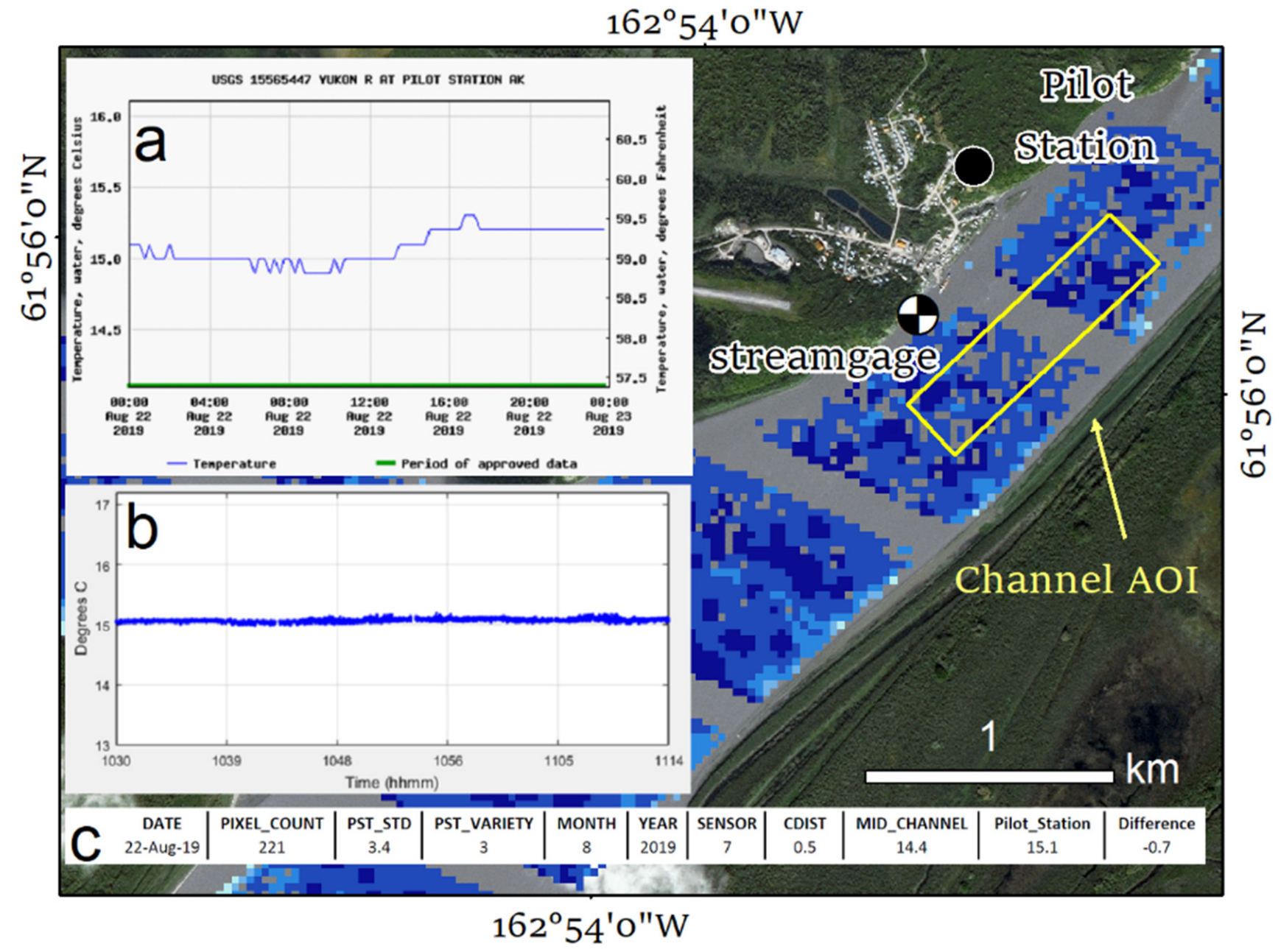

Figure 3. Example of concurrent measurements from: (a) automated streamgage system; (b) manual water temperature profile; and (c) remotely sensed provisional surface temperature (pST) estimate (MID_CHANNEL $\left({ }^{\circ} \mathrm{C}\right)$ ) and associated parameters (DATE, PIXEL_COUNT, PST_STD $\left({ }^{\circ} \mathrm{C}\right)$, PST_VARIETY, MONTH, YEAR, SENSOR, CDIST $(\mathrm{km})$, Pilot Station $\left({ }^{\circ} \mathrm{C}\right)$, Difference $\left.\left({ }^{\circ} \mathrm{C}\right)\right)$.

Agreement between pST and streamgage data for the broader $1 \mathrm{~km}$ Swath AOI was also very good $\left(\mathrm{RMSE}=2.39^{\circ} \mathrm{C}, \mathrm{r}^{2}=0.84, p\right.$-value $\left.<<0.01\right)$. There is slightly less agreement 
$\left(\mathrm{RMSE}=2.52^{\circ} \mathrm{C}, \mathrm{r}=0.844, \mathrm{r}^{2}=0.78, p\right.$-value $\left.=<<0.01\right)$ for the upstream meander zone (Table 1). All AOIs received between 50 and 60 sample dates with the smallest AOI (Channel) attaining the least $(n=52)$ samples and the largest AOI (Meander) attaining the greatest $(n=59)$ sample size (Table 1$)$. There were 47 sample dates common to all three AOIs, with six sample dates common to two of the three AOIs and 11 dates where only one of the three AOIs was acquired.

\subsection{Provisional Surface Temperature Estimates at the $10 \mathrm{~km}$ Scale}

Analysis showed all 21 of the river segments have good to very good agreement between pST and in situ water temperatures made on the same day at the Pilot Station streamgage location (Figure $4 \mathrm{a}$, Table 2 ). On average, river segments received quality pixels from unique collections of $105 \pm 18$ ARD scenes. The greater sample size of contributing scenes-compared to the Swath, Channel, and Meander AOIs-is due to the larger area of the river segments, which increases the likelihood of quality pixels occurring within the bounds. RMSE values range between $2.0^{\circ} \mathrm{C}$ and $3.44{ }^{\circ} \mathrm{C}$. The average Pearson's correlation for all segments was $0.90 \pm 0.05$ with an average $r^{2}$ of $0.80 \pm 0.08$ (Table 2). The poorest agreement came from Section $2\left(\mathrm{RMSE}=3.44{ }^{\circ} \mathrm{C}, \mathrm{r}^{2}=0.59\right)$ while the best agreement came from Section $3\left(\mathrm{RMSE}=2.00{ }^{\circ} \mathrm{C}, \mathrm{r}^{2}=0.89\right)$ (Table 2$)$.
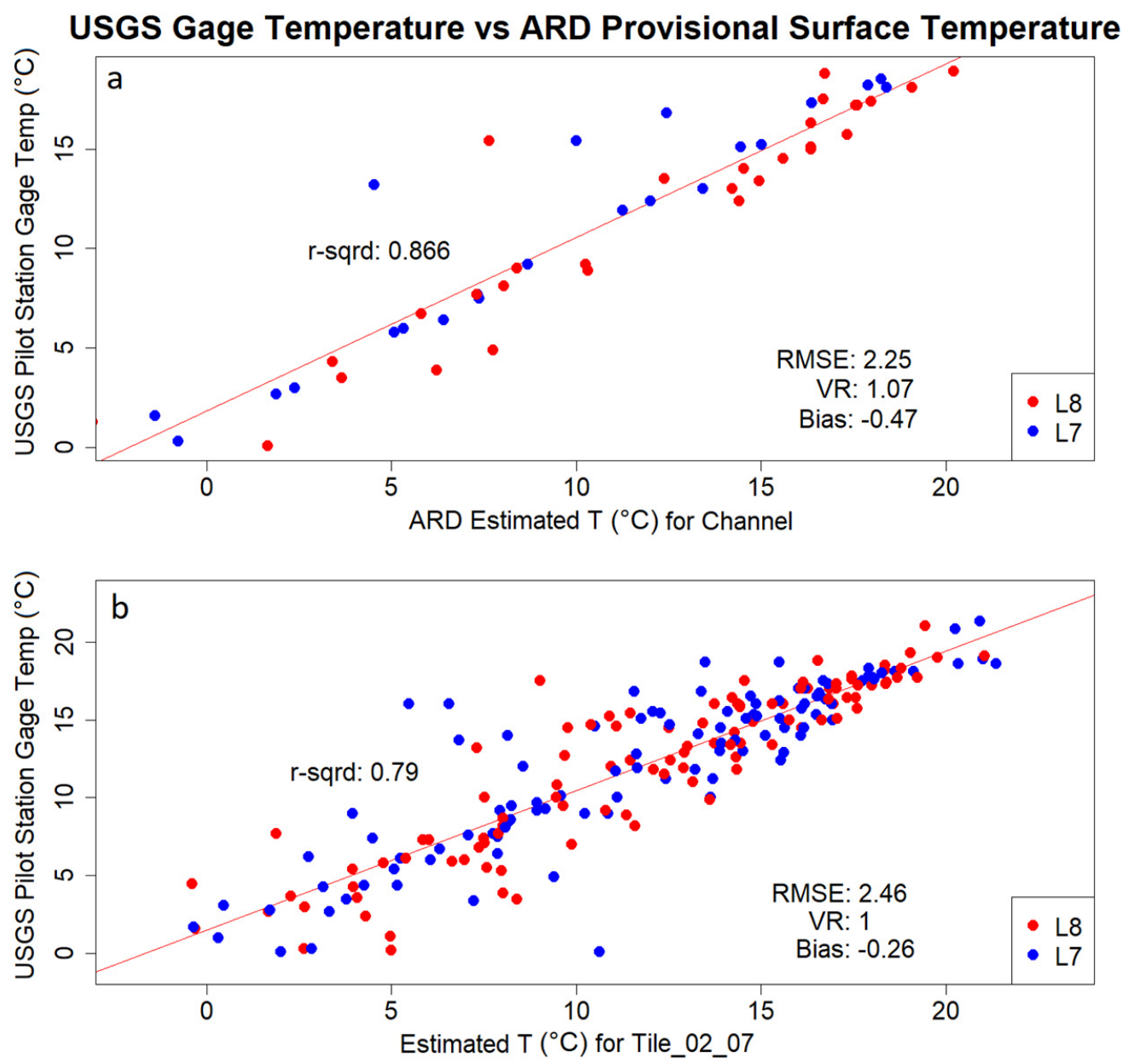

Figure 4. Agreement between USGS streamgage measurements and ARD estimates averaged over the (a) Channel AOI and (b) the portion of the Yukon River captured by ARD tile AK-0207. 
Table 2. Summary of agreement between river sections and USGS streamgage data.

\begin{tabular}{|c|c|c|c|c|c|c|c|c|}
\hline Segment & $\mathbf{n}$ & $\hat{\bar{y}}\left({ }^{\circ} \mathrm{C}\right)$ & $\bar{y}\left({ }^{\circ} \mathrm{C}\right)$ & $\operatorname{RMSE}\left({ }^{\circ} \mathrm{C}\right)$ & VR & $\operatorname{Bias}\left({ }^{\circ} \mathrm{C}\right)$ & $r^{2}$ & $p$-Value \\
\hline 3 & 73 & 12.44 & 12.09 & 2.00 & 1.00 & 0.35 & 0.89 & $4.9 \times 10^{-36}$ \\
\hline 4 & 82 & 11.92 & 11.85 & 2.08 & 1.06 & 0.08 & 0.88 & $3.8 \times 10^{-39}$ \\
\hline 5 & 123 & 11.67 & 11.37 & 2.49 & 1.04 & 0.29 & 0.82 & $4.5 \times 10^{-47}$ \\
\hline 6 & 119 & 11.31 & 11.37 & 2.37 & 1.04 & -0.06 & 0.83 & $1.7 \times 10^{-47}$ \\
\hline 7 & 123 & 11.56 & 11.55 & 2.52 & 1.01 & 0.00 & 0.80 & $1.4 \times 10^{-44}$ \\
\hline 8 & 123 & 11.6 & 11.71 & 2.71 & 1.03 & -0.11 & 0.78 & $2.1 \times 10^{-41}$ \\
\hline 9 & 128 & 11.63 & 11.52 & 2.62 & 1.03 & 0.11 & 0.78 & $4.4 \times 10^{-44}$ \\
\hline 10 & 130 & 12.04 & 11.74 & 2.62 & 1.02 & 0.30 & 0.78 & $8.5 \times 10^{-44}$ \\
\hline 11 & 121 & 11.50 & 11.62 & 2.28 & 1.06 & -0.11 & 0.84 & $6.5 \times 10^{-50}$ \\
\hline 12 & 91 & 12.47 & 12.59 & 2.31 & 1.02 & -0.13 & 0.80 & $2.4 \times 10^{-32}$ \\
\hline 13 & 126 & 12.18 & 11.73 & 2.60 & 1.01 & 0.45 & 0.79 & $1.9 \times 10^{-44}$ \\
\hline 14 & 80 & 11.79 & 11.86 & 2.32 & 0.97 & -0.08 & 0.83 & $3.5 \times 10^{-32}$ \\
\hline 15 & 75 & 11.94 & 11.85 & 2.41 & 0.95 & 0.1 & 0.80 & $6.6 \times 10^{-28}$ \\
\hline 16 & 107 & 12.54 & 12.5 & 3.05 & 0.95 & 0.05 & 0.65 & $1.3 \times 10^{-25}$ \\
\hline 17 & 108 & 12.71 & 12.74 & 2.57 & 0.94 & -0.03 & 0.73 & $7.1 \times 10^{-33}$ \\
\hline 18 & 115 & 12.29 & 12.62 & 2.11 & 0.95 & -0.33 & 0.83 & $1.9 \times 10^{-45}$ \\
\hline 19 & 107 & 11.97 & 12.50 & 2.19 & 1.01 & -0.54 & 0.83 & $2.3 \times 10^{-42}$ \\
\hline 20 & 113 & 12.25 & 12.62 & 2.71 & 1.01 & -0.39 & 0.72 & $5.0 \times 10^{-33}$ \\
\hline 21 & 114 & 12.44 & 12.49 & 3.44 & 1.05 & -0.05 & 0.59 & $1.1 \times 10^{-23}$ \\
\hline 22 & 86 & 12.12 & 12.27 & 2.85 & 0.93 & -0.15 & 0.70 & $3.3 \times 10^{-24}$ \\
\hline 23 & 85 & 11.88 & 12.34 & 2.48 & 0.96 & -0.47 & 0.78 & $2.1 \times 10^{-29}$ \\
\hline 24 & 87 & 12.38 & 12.54 & 2.26 & 0.97 & -0.17 & 0.80 & $1.5 \times 10^{-31}$ \\
\hline $\begin{array}{l}\text { ARD } \\
\text { Tile }\end{array}$ & 209 & 11.87 & 12.13 & 2.46 & 1.00 & -0.26 & 0.79 & $2.3 \times 10^{-73}$ \\
\hline
\end{tabular}

Note: RMSE is the root mean squared error; VR is the variance ratio.

\subsection{Provisional Surface Temperature Estimates at the $100 \mathrm{~km}$ Scale}

There were 209 days where Landsat overflights captured some portion of the Yukon River within the ARD tile on the same day USGS streamgage measurements were recorded. In comparing the daily USGS streamgage measurement with the estimated mean pST for the entire portion of the Yukon River captured within the ARD tile, we also found good $\left(\mathrm{r}^{2}\right.$ of 0.79$)$ agreement (Figure $\left.4 \mathrm{~b}\right)$ with an overall RMSE $=2.46^{\circ} \mathrm{C}, \mathrm{VR}=1.0$, and a bias of $-0.26^{\circ} \mathrm{C}$. Similar to the Channel AOI at the $1 \mathrm{~km}$ scale, the temperature estimates at this largest scale are slightly negatively biased (Figure $4 \mathrm{~b}$ ).

\subsection{Error Analysis}

Analysis of the residuals was restricted to the Channel AOI since this represents the most direct comparison of the two data streams. The area of the Channel AOI spanned 339 pixels ( $\approx 31$ hectares). Within the Channel AOI, the number of contributing pixels did not have a significant effect on the correlation $\left(r^{2}=0.009, p\right.$-value $\left.=0.496\right)$ between the observed and the estimated water temperatures (Figure 5a). Estimates based on fewer pixels are due to cloud or cloud shadow obscuring the AOI, or in the case of scenes acquired by Landsat 7, due to SLC failure [40]. During late spring and early winter, the presence of ice in the river can also obscure the water. The standard deviation of the mean pST estimate within the AOI did significantly $(p$-value $<<0.05)$ correlate with the accuracy 
of pST estimates (Figure $5 b)$; however, the relationship was poorly defined $\left(r^{2}=0.487\right)$. Similarly, the variety of values (the number of unique values for all pixels in the AOI) that contribute to the mean of the AOI is negatively correlated with accuracy (Figure $5 c$ ). The relationship is also significant ( $p$-value $<<0.05)$ but poorly defined $\left(\mathrm{r}^{2}=0.409\right)$ and largely influenced by multiple outlying data points.
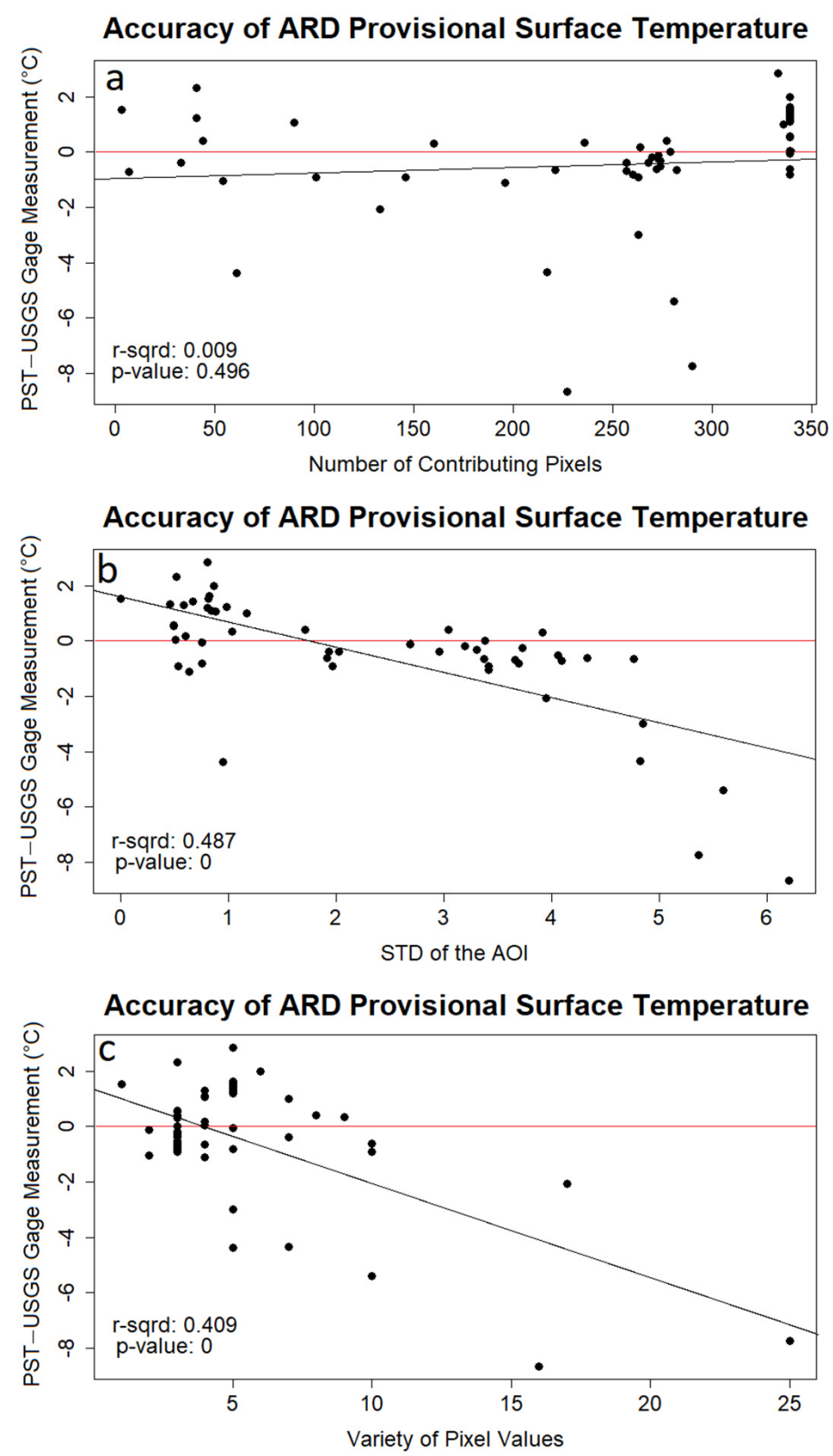

Figure 5. Scatter plots showing how the attributes of (a) quality pixel count, (b) standard deviation (STD) of the mean estimate, and (c) variety of quality pixel values are correlated with the agreement between the estimated and observed water temperature.

We detected no statistical correlation $\left(\mathrm{r}^{2}=0.015, p\right.$-value $\left.<<0.384\right)$ of the pST agreement with proximity to clouds (Figure 6). The month and year of acquisition had no significant influence on the accuracy of the estimates either, as the $p$-value was 0.246 and 0.742 , respectively. The majority of the estimated water temperature data points fall within \pm 2 degrees of the recorded water temperature across all months and all years (Figure 7). 


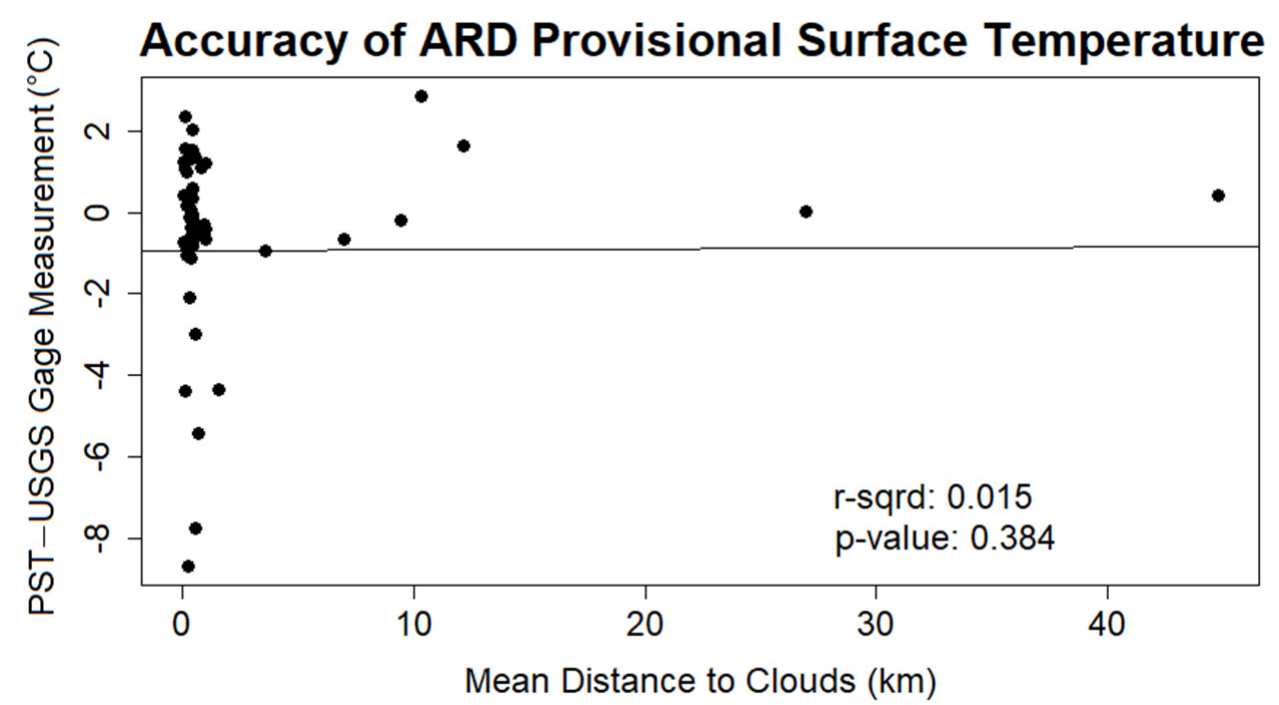

Figure 6. Scatter plot showing how the mean distance to cloud from all quality pixels within the Channel $\mathrm{AOI}$ is correlated with the agreement between the estimated and observed water temperature.
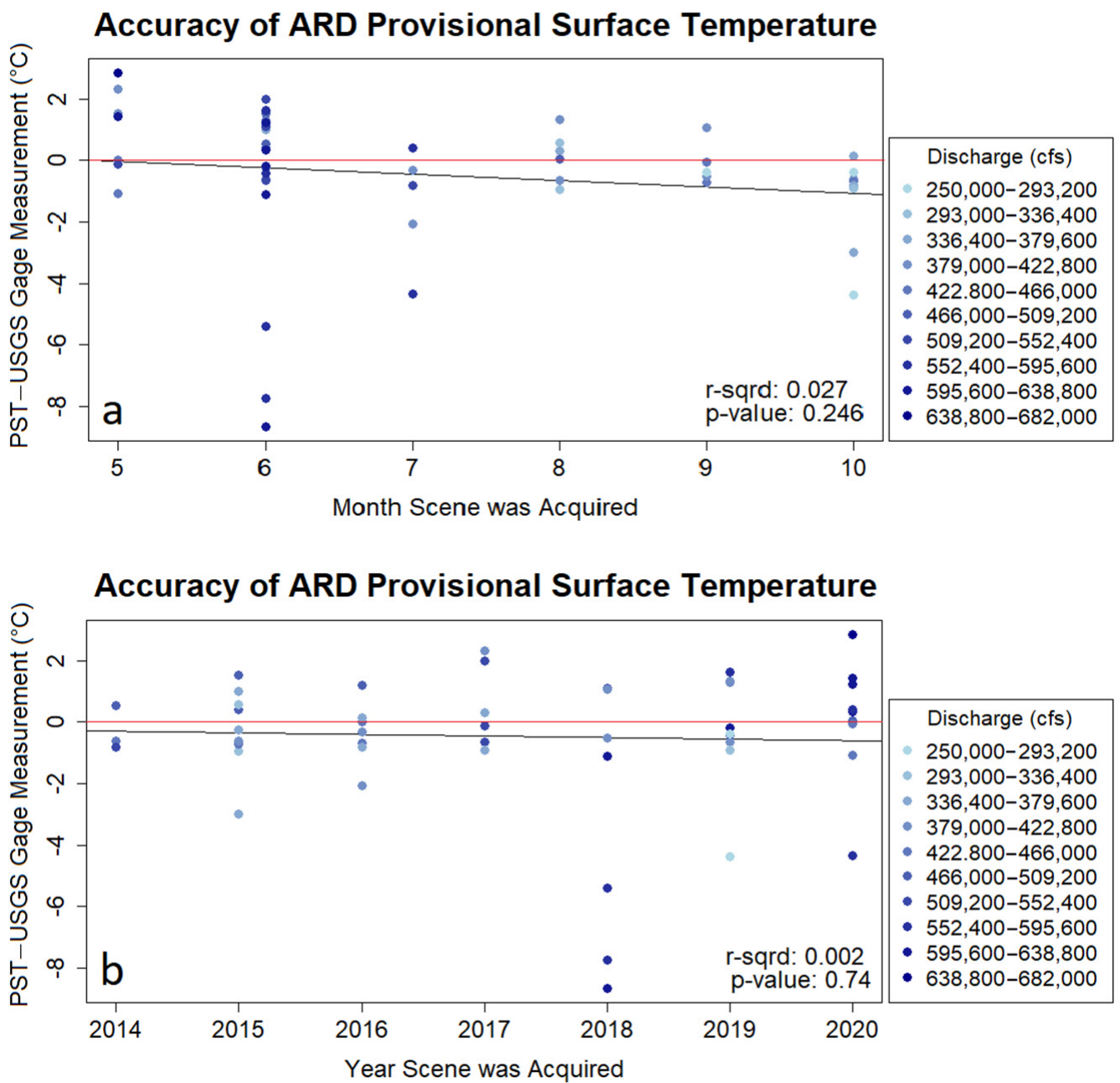

Figure 7. Scatter plots showing how the attributes of (a) month of acquisition and (b) year of acquisition can influence the agreement between the estimated and observed water temperature. Data points are color-coded according to river discharge. 
Landsat 8 had slightly better accuracy and agreement in estimating water temperature compared to Landsat 7 (Figure 8). RMSE was $2.04{ }^{\circ} \mathrm{C}$ for Landsat 8 and a TIRS sensor compared to RMSE $=2.50{ }^{\circ} \mathrm{C}$ for Landsat 7 and the ETM+. Both sensors had a median residual value very close to zero with uniform interquartile spread in the data above and below the median. The bias score for the ETM+ was $-1.32{ }^{\circ} \mathrm{C}$ (estimated water temperature to be slightly lower than what was recorded), while the TIRS sensor had a bias of $0.16{ }^{\circ} \mathrm{C}$ (estimates were slightly higher than recorded values). Both Landsat platforms produced outlying data points where estimated temperature differed by more than 3 degrees from the measured temperatures. Landsat 7 collected four estimates that were significantly different from the recorded temperatures. Landsat 8 had two dates with similar results. In all cases, these estimates were colder than the measured temperature.



Figure 8. Boxplot depicting how the sensor used for acquiring the water temperature estimate influences the accuracy of estimated water temperature; Landsat 7 carries the Enhanced Thematic Mapper Plus (ETM+) while Landsat 8 carries the Thermal Infrared Sensor (TIRS).

\section{Discussion}

The relatively good agreement between the Channel AOI temperature estimates and Pilot Station streamgage data support the use of remotely sensed provisional surface temperature data for estimating the water temperature within the Yukon River and potentially other large, remote, well-mixed rivers. The average daily water temperatures acquired from both remote and in situ systems differed, on average, by less than half a degree Celsius for the study period. Estimates within our study achieved an RMSE of $2.25{ }^{\circ} \mathrm{C}$ at the $1 \mathrm{~km}$ scale and an RMSE of $2.46^{\circ} \mathrm{C}$ at the $100 \mathrm{~km}$ scale. Bias was $-0.47^{\circ} \mathrm{C}$ for the Channel AOI and $-0.26{ }^{\circ} \mathrm{C}$ for the entire river within the ARD tile, indicating that the ARD pST estimates are slightly cooler than the actual water temperature and offering a factor for potential future corrective measures.

The variation in the agreement of river AOIs suggests that river morphology, geography, and other environmental conditions affect the measurement agreement. For example, there was a slight decrease in accuracy and an increase in RMSE when pST was 
derived using the Swath AOI, which can be explained by the inclusion of near-shore pixels that tend to appear warmer than mid-channel pixels. This is further reflected in the bias, which becomes positive. Subsequently, pST estimates that include nearshore pixels, and especially within smaller AOIs such as the Swath AOI, may produce estimates warmer than streamgage measurements (Table 1).

There was further disagreement when comparing in situ data to the more distant Meander AOI. Again, the RMSE slightly increases, and the bias is slightly less negative compared to the Channel AOI $\left(-0.22^{\circ} \mathrm{C}\right.$ compared to $-0.26^{\circ} \mathrm{C}$, respectively). The Meander AOI is approximately $3 \mathrm{~km}$ upstream of the Swath and Channel AOI as well as the USGS streamgaging station. The water passing through the Meander AOI and sensed by the respective Landsat sensors would be the same water contributing to the same-day daily average temperature recorded by the USGS streamgage, so it should not be assumed that the kinetic water temperature is significantly different between the two areas due to temporal separation. The morphology of the Meander AOI is significantly different from the single channel near Pilot Station. Fluctuating water levels can create areas of shallow water, decrease water velocity, and expose islands and sandbars, all of which appear to result in warmer water estimates and potentially negatively affect accuracy. The flow direction of the river is different here compared to the Channel AOI, and it is possible that surface winds could produce unique water surface conditions that are known to influence emissivity and subsequent pST estimates [15]. The Meander AOI also corresponds with the confluence of the Chuilnak River. Water temperature from the Chuilnak River is not available, but the clear, meandering, lowland setting suggests it may have slightly warmer temperatures than that of the Yukon. Contribution of this water to the main flow of the Yukon within the Meander AOI could also explain a greater divergence in the estimated water temperature [15].

In all cases, agreement was statistically good, but the variation signifies that several factors should be considered when anticipating the use of these data. The average accuracy of the estimated water temperature may or may not be adequate depending on the application. Jimenez et al. [27] considered RMSE values $<0.7 \mathrm{~K}$ to be "good" and RMSE $<2$ ${ }^{\circ} \mathrm{K}$ to be "acceptable" when deriving land surface temperature estimates using a refined single channel algorithm. Laraby and Schott [41] reported RMSE values ranging from 0.51 to $3.46 \mathrm{~K}$ when validating the Landsat 7 derived land surface temperatures at the global scale. The accuracy of the estimates within our study ranged from an RMSE of $2.25^{\circ} \mathrm{C}$ at the $1 \mathrm{~km}$ scale to an RMSE of $2.46^{\circ} \mathrm{C}$ at the $100 \mathrm{~km}$ scale. The suitability of this accuracy thus becomes dependent on the application. In the absence of any other available data or where more refined processing of TIR data is prohibitive, an RMSE $<3^{\circ} \mathrm{C}$ is arguably good and very useful. However, we acknowledge that some ecological or biochemical processes are sensitive to changes in water temperature that may be too fine to be resolved using the pST product. Alternatively, seasonal modeling of river temperature or a long-term trend analysis may be more permissible given the tolerance for coarser datasets.

The temporal availability of pST should also be considered. The relative paucity of the pST data compared to an in situ data collection system can dictate how these data can be used. Presently, the frequency of the pST estimates is weekly under ideal sky conditions, utilizing the combined and offset return intervals of Landsat 7 (to be replaced by Landsat 9 in 2021) and Landsat 8. In northern and southern latitudes, increasing the overlap of swaths produces sidelap, which can further shorten the acquisition frequency of pST at a given location. Conversely, regions with increased sidelap also experience increased average cloud over, which impedes surface measurements despite overflights. One tradeoff of this infrequency is that large areas of interest can be measured simultaneously and repeatedly on a potentially global scale. In the case of this study, the pST data offer an exceptionally unique tool for acquiring concurrent measurements of water temperature for a very large and remote river system that would otherwise be prohibitively expensive and logistically demanding to densely instrument. The historical archive available through the Landsat program also offers a unique resource for retroactively monitoring hydrologic 
systems. Applications requiring daily or hourly data would of course require in situ monitoring systems.

Intersegment variability is significant across our study area with respect to segment shape and river morphology. While we did not quantify the variation, qualitative observation reveals key attributes to certain segments, and we reported agreement on a segment-by-segment basis to illustrate the accuracy and utility of pST within the diverse range of segment morphology (Appendix A, Figures A1-A22). River segments with large sloughs (segments 9, 10,13,15, and 16) maintain good to very good agreement with RMSE values ranging between $2.41{ }^{\circ} \mathrm{C}$ (segment 15 ) and $3.05^{\circ} \mathrm{C}$ (segment 16) and with $\mathrm{r}^{2}$ values ranging from 0.65 (segment 15) to 0.80 (segment 16). Sloughs offer a chance for water velocity to decrease, stratify, and potentially be estimated as warmer, thereby skewing the overall mean estimates. While this may be the case within these segments, it does not appear to significantly degrade agreement. Similarly, segments that contain large areas of backwater, isolated ponds, and other water bodies (segments 4, 11, 14, and 21) had varying degrees of agreement with the streamgage data, but we did not observe any overall trend (e.g., a negative correlation in agreement with increasing area of backwater). A qualitative analysis found instances of "warm water" pixels corresponding with locations that appear to be very shallow water or recently exposed sand or gravel bars and ideally should be classified as land. Without ground truth data, it is difficult to know the exact nature of these surfaces. While we are uncertain of the root cause of this misclassification, we are confident that the overall contribution of these pixels is insignificant when included in segment or whole tile statistics. It is important to acknowledge that fluctuations of the river stage in combination with scene-specific atmospheric conditions result in every pST acquisition event being somewhat unique. Sand and gravel bars can appear and disappear with seasonal changes in river stage and annual changes in river morphology. Fog, cirrus clouds, or smoke that is present in the atmosphere but too subtle to be automatically detected may slightly influence the estimated water temperature in one location but not another and inconsistently over time. Ultimately, the data support the possibility of inferring water temperature on a given day from any available Landsat ARD data even if this is not in the immediate vicinity of the point of interest. Utilization of the entire length of the river within the ARD tile resulted in four times the available Landsat scenes. Despite significant distances between river segments and the Pilot Station streamgage and significant intersegment morphological variation, agreement with the streamgage data was good for nearly all distal river segments.

A fundamental limitation to the pST is due to it being downscaled. The pST product is downscaled to $30 \mathrm{~m}$ resolution from the original $100 \mathrm{~m}$ resolution thermal bands on all Landsat platforms. Therefore, the optimal agreement between pST estimates and in situ measurements can be found in water bodies where the width and/or diameter are much greater than $100 \mathrm{~m}$ [18]. The Yukon River is an ideal waterbody for this study, given that its width is regularly well over $1 \mathrm{~km}$ and it is not subject to rapid changes in discharge or water temperature. While small lakes, narrow sloughs, creeks, and streams are discernable within our study, they are likely influenced by the land surface temperature recorded in adjacent pixels, which is regularly discernable within our study area. Finally, the Yukon River is an ideal environment to employ ARD-derived pST estimates due to its size and the nature of a well-mixed water column that does not support thermal stratification. Stratification is more pronounced in large lakes and rivers within temperate climates, which could limit the practicality of our methods if employed elsewhere.

\section{Sources of Error}

There are numerous potential sources of error based on the environmental conditions at the time of scene acquisition (atmospheric profiles, water surface conditions, air temperature, and water turbidity), but these are difficult or impossible to quantify retroactively. Atmospheric water vapor is a known significant contributor of error within single channel algorithms [27]. In the case of ARD pST estimates, water vapor is assumed based on static, 
mean ASTER GED climatology maps, and subsequently it misses unique daily conditions that, if known, could improve pST agreement. Similarly, water surface roughness can influence TIR signatures [15], but is not included as a condition within ARD pST derivation and is impossible to retroactively quantify for error analysis. Atmospheric transmissivity and proximity to clouds were two factors found to significantly affect the accuracy of global Landsat 7 land surface temperature estimates [41]. Land surface temperature estimates from pixels with greater transmission values and greater distances from clouds produced smaller RMSE values.

The number, distribution, and variability of quality pixels within a scene is indirectly related to the aforementioned environmental conditions present during scene acquisition. While we may not know the exact mechanism, an analysis of these pixels can account for some portion of pST error. Positive and negative residuals occur across the range of pixel count, suggesting that missing data, due to the cloudiness of a scene (at least below cloud cover of $80 \%$ ) or due to SLC failure, does not influence the accuracy of water surface estimates.

The standard deviation relates to the variability of the pixel values contributing to the mean estimate. In our study, a high standard deviation most often represents an AOI or river segment with a complex water surface influenced by variable water depths and proximity to shorelines. A low standard deviation most often represents AOIs or river segments with even and consistent water surfaces such as those found where the river is confined to a single channel. The greatest agreement occurred with a standard deviation between 1 and 3 degrees (Figure $5 b$ ). For standard deviations increasingly above this range, provisional surface temperature estimates become increasingly colder than concurrent in situ measurements. This produces a negative difference. For standard deviation less than 1 degree, pST estimates appear to be warmer than the concurrent in situ measurements, thereby producing a positive difference.

We found that with regard to the variety of quality pixel values that occur within an AOI, the mean estimated surface water temperature with variety values of 1-4 had the highest accuracy (Figure 5c). An increase in variety values above four begins to degrade the accuracy of the estimate. High variety values come from AOIs with complex water surfaces influenced by variable water depths and proximity to shorelines while low values come from the even and consistent water surfaces such as those found in single linear channels.

Within this study, the distance to clouds was not significantly correlated with the residuals. However, a slight pattern exists where the dates corresponding to quality pixels with greater distances from clouds $(>10 \mathrm{~km})$ consistently produce estimates within $2{ }^{\circ} \mathrm{C}$ of the true water temperature. This condition is ideal for remote sensing but very rare with only $\mathrm{n}=4$ of the 52 dates sampled for the Channel AOI meeting this criterion. Dates with quality pixels with distance-to-cloud values $<10 \mathrm{~km}$ have a greater chance of being less accurate, but overall they produce good agreement with the majority of pST estimates falling within $2{ }^{\circ} \mathrm{C}$ of streamgage measurements (Figure 6).

Historical field observations indicate that thermal stratification is greatest at the Pilot Station streamgage during increased river discharge. Stratified water columns could negatively impact pST estimates. We color coded the residuals according to river discharge. Darker blue indicates greater discharge and higher river stage. Thermal stratification, when present, is minimal with variation in the vertical water column being $\pm 0.8^{\circ} \mathrm{C}$. We report no correlation of accuracy with river discharge (Figure 7). Agreement within $\pm 2{ }^{\circ} \mathrm{C}$ exists for both high and low discharge conditions.

While the Landsat ARD data are radiometrically calibrated across all sensors, we still found some difference in estimates derived from different sensors. Overall, this difference was very small, and there was good agreement for both sensors. If the aforementioned outliers were restricted to break-up or freeze-up seasons, they could be the product of snow and ice contamination, but these outliers come from across the ice-free season. It is most likely that atmospheric conditions such as thin cirrus clouds, smoke, or other conditions are obscuring or interfering with land surface radiation. A detailed investigation into these 
anomalies could help inform future application of pST. With detailed and machine readable metadata, such anomalous dates could be further winnowed from analysis.

\section{Conclusions}

- Landsat ARD provisional surface temperature for the lower Yukon River strongly agrees with in situ water temperature measurements. Approximately $90 \%$ of the variation seen within in situ measurements is reflected in remotely sensed estimates.

- Remotely sensed estimates for the Channel AOI adjacent to the Pilot Station streamgage, achieved an RMSE of $2.25^{\circ} \mathrm{C}$ compared to in situ measurements.

- For the Yukon River and within our study area, we found similarly good agreement between the Landsat ARD provisional water surface temperature and in situ water temperature measurements taken from areas of interest (AOIs) and river segments distributed upstream or downstream of Pilot Station, Alaska.

- At least in the case of large unstratified rivers in Alaska, ARD pST can be used to infer water temperature at a given point based on immediate and geographically distant river reaches in the event of limited scene availability due to cloud cover, a common problem in northern latitudes.

- $\quad$ PST is downscaled to a $30 \mathrm{~m}$ resolution from the original $100 \mathrm{~m}$ resolution thermal bands. Optimal agreement between pST estimates and in situ measurements can be found in water bodies where width and/or diameter are much greater than $100 \mathrm{~m}$. Small lakes, narrow sloughs, creeks, and streams, while discernable, are likely to be contaminated by the land surface temperature recorded in adjacent pixels.

- The Yukon river is a large, glacially fed, free flowing river. While it is the largest of such rivers in Alaska it shares many attributes with other large rivers in the state, namely the Tanana, Susitna, Colville, and Copper River. Our analysis suggests that the methods outlined in this study could also be used to augment existing monitoring networks, collect estimates from locations where physical monitoring is impossible, or provide historical estimates from trend analysis.

Author Contributions: Conceptualization, J.S.C.; methodology, C.A.B.; validation, C.A.B.; writingoriginal draft preparation, C.A.B.; writing-review and editing, C.A.B. and J.S.C.; visualization, C.A.B.; supervision, J.S.C.; project administration, J.S.C.; funding acquisition, J.S.C. All authors have read and agreed to the published version of the manuscript.

Funding: This research was funded by the U.S. Geological Survey National Land Imaging Program.

Institutional Review Board Statement: Not applicable.

Informed Consent Statement: Not applicable.

Data Availability Statement: Not applicable.

Acknowledgments: The authors wish to thank John W. Jones, Research Geographer at the USGS Leetown Science Center, and three anonymous reviewers for constructive and critical reviews that greatly improved the quality of this manuscript.

Conflicts of Interest: The authors declare no conflict of interest. Any use of trade, firm, or product names is for descriptive purposes only and does not imply endorsement by the U.S. Government. 


\section{Appendix A}

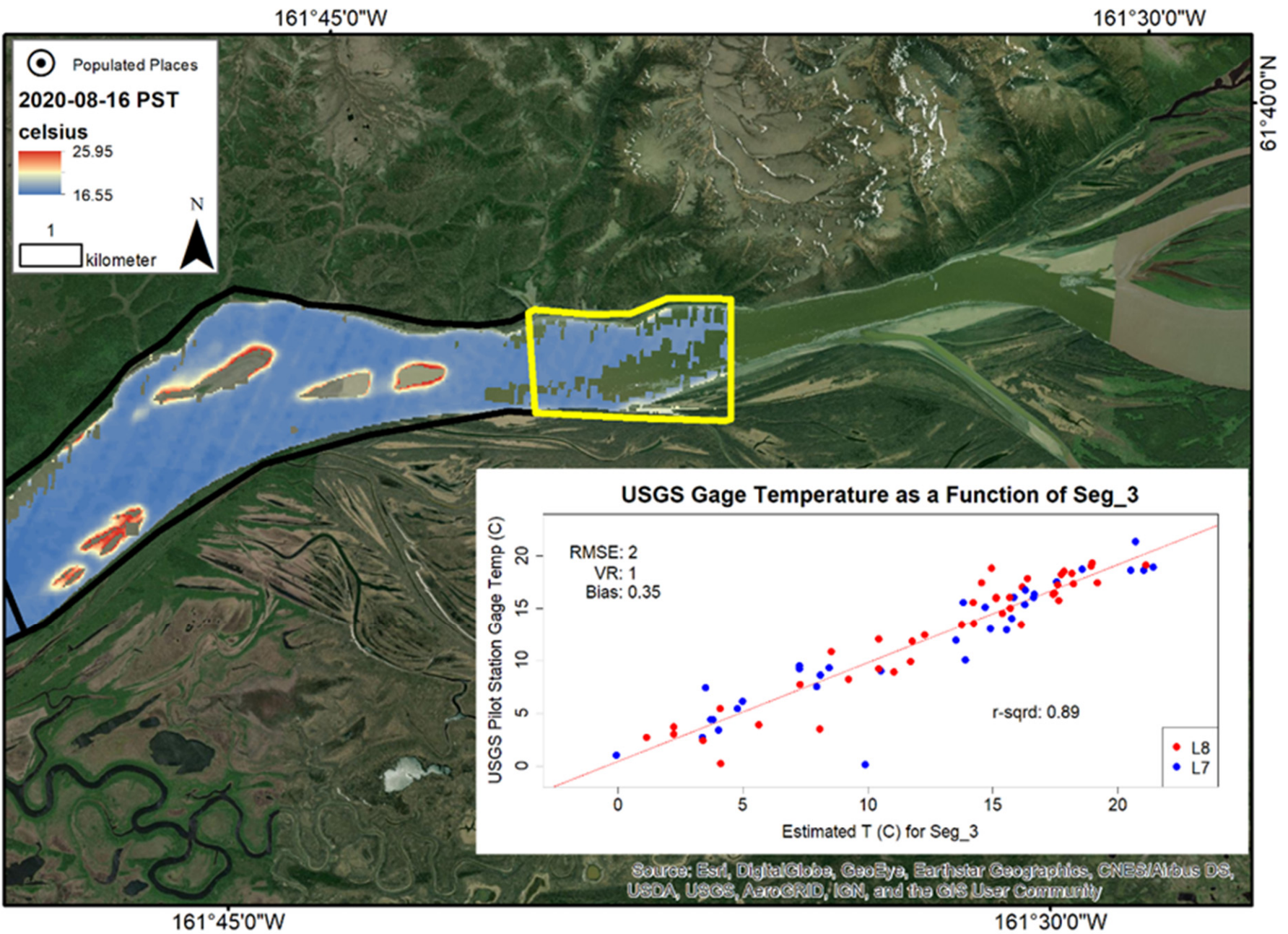

Figure A1. Segment 3 is the most upstream segment in the analysis and the single river segment with a river length of $3 \mathrm{~km}$. Within this segment the Yukon River occupies a single channel with rolling uplands of the Ilivit Mountains to the north and vegetated floodplains to the south. Nearly half the river channel is covered by a permanent NoData gap. These NoData gaps are permanent gaps in the ARD dataset due to missing data within the Advanced Spaceborne Thermal Emission and Reflection Radiometer (ASTER) Global Emissivity Database (GED), i.e., an auxiliary input used in the derivation of pST [26]. Agreement between estimated water temperature within this segment and corresponding temperature records at Pilot Station was good $\left(\mathrm{RMSE}=2{ }^{\circ} \mathrm{C}, \mathrm{r}^{2}=0.89\right.$ ) despite a 100 river mile separation. At average flow speeds of $8-13 \mathrm{~km} / \mathrm{h}$, water passing through this segment is $12-8 \mathrm{~h}$ upstream from the Pilot Station gaging station. 


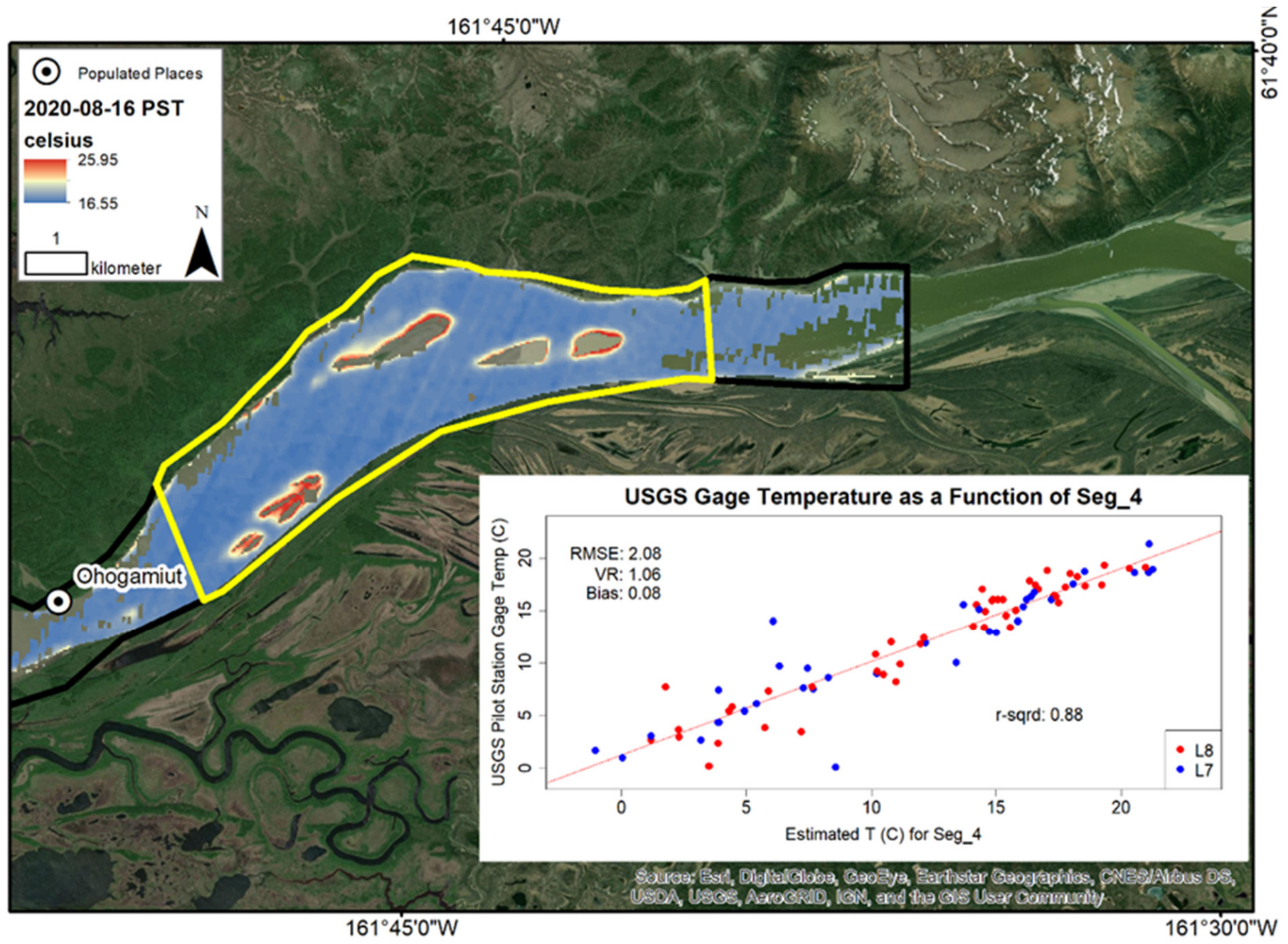

Figure A2. Within segment 4, the river is a single channel with several mid-channel islands that become submerged during high river stages and are barren sand bars at low river stage as indicated by a lack of permanent woody vegetation. In the scene above, water levels on 16 August 2020 were low enough to expose the islands. They present as lenticular data gaps with warm-water margins. Note the visual difference between these data gaps and the permanent NoData gaps within Segment 3. Agreement between estimated water temperature and streamgage data is good $\left(\operatorname{RMSE}=2.08{ }^{\circ} \mathrm{C}, \mathrm{r}^{2}=0.88\right)$. The north shore of the river is rolling uplands of the Ilivit Mountains with steep bluffs along the river, including Serpentine Bluff. The southern shore of the river is vegetated flood plain with numerous crescentic abandoned channels. 


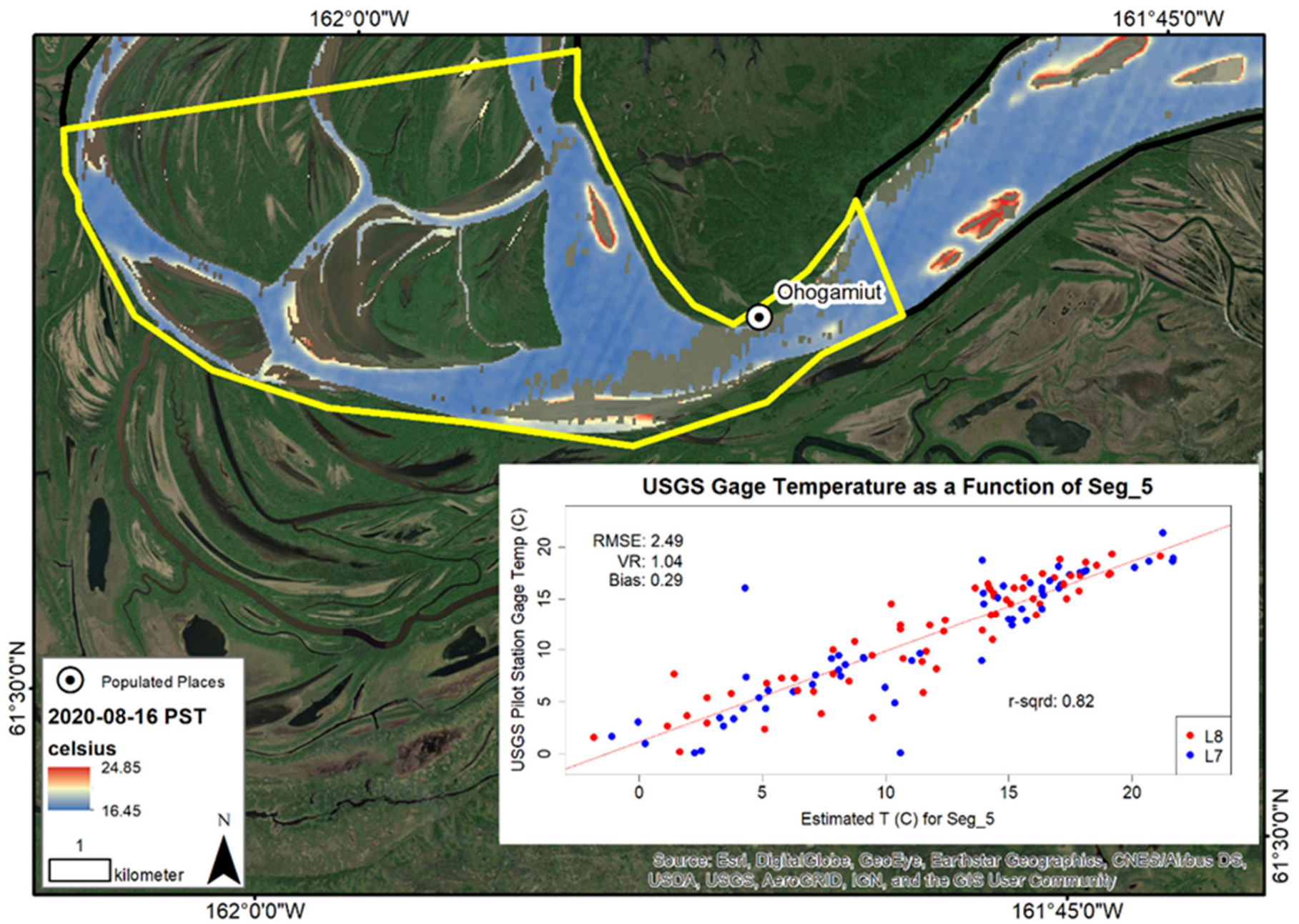

Figure A3. Segment 5 captures the first large bend in the Yukon River after it enters the ARD tile and rounds the southwest terminus of the Ilivit Mountains. The river bends to the north and splits into numerous channels as it bisects Willow Island, Blade Island, and Blue Fish Island. Willow Island, the large upstream island visible in the scene, is prone to partial inundation during high water stages. With the addition of multiple channels and large islands, the ratio of surface water to shoreline decreases. This allows for estimates of water temperature to be more significantly influenced by warmer nearshore water. However, correlation with corresponding temperature measurements remains good $\left(\mathrm{RMSE}=2.49^{\circ} \mathrm{C}, \mathrm{r}^{2}=0.82\right)$ and suggests that the majority of the Landsat passes capture enough open water to provide a reasonable estimate that is not significantly influenced by nearshore warm water. A NoData gap is also present at the apex of the meander. 


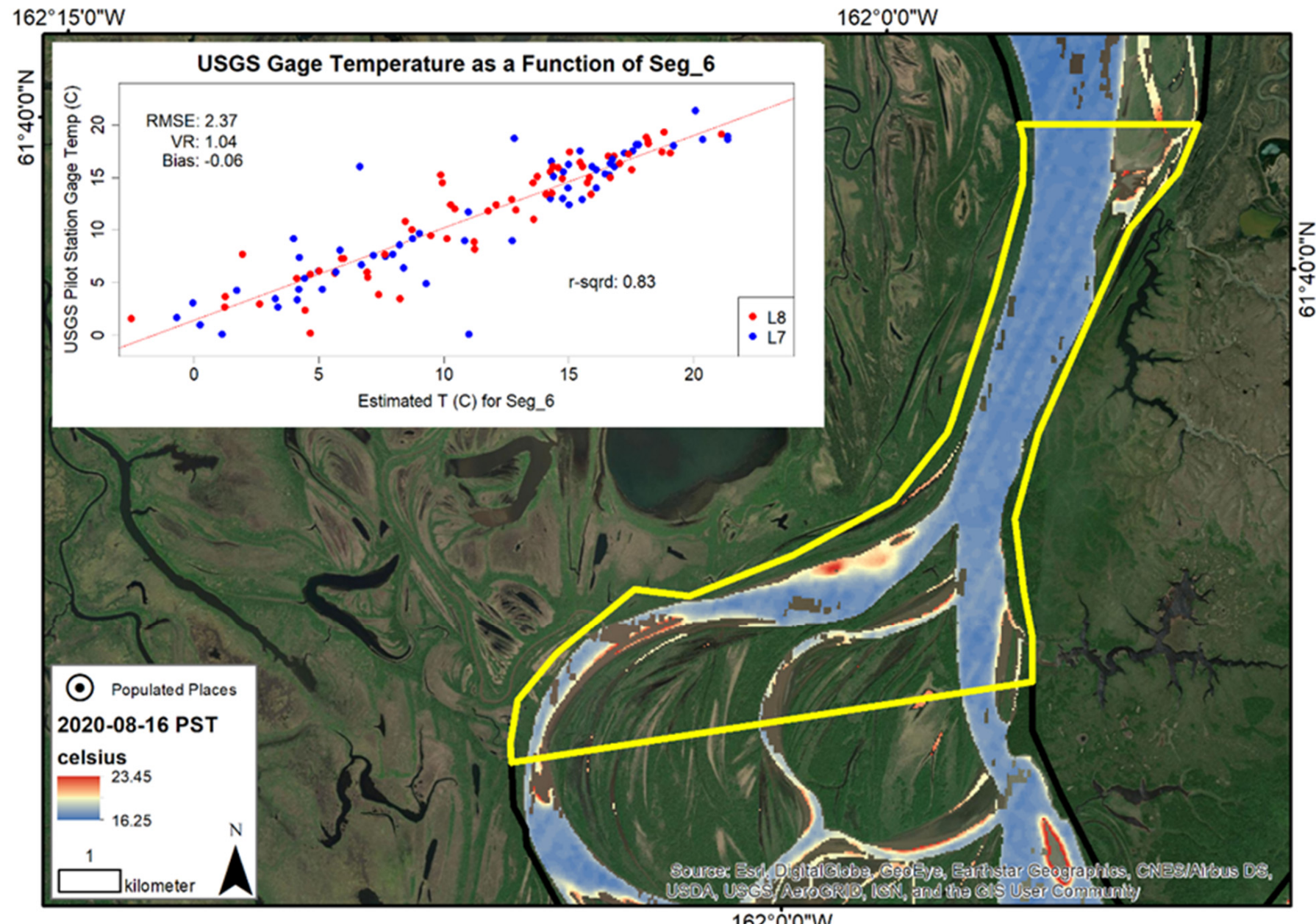

Figure A4. Segment 6 is characterized by the union of three channels (Devil's Elbow, Middle Slough, Cross Slough, respectively) after passing by large islands. The east shore of the river abuts the rolling uplands of the Ilivit Mountains while the west shore is adjacent to boggy lowlands dissected by lakes, ponds, and creeks. In the scene above, submerged sandbars produce warm water features. At lower stages, these areas are characterized as dry land and omitted. At higher stages, they are not visible and appear as even-temperature open water. Multiple, small NoData gaps occur in the Devil's Elbow channel as the river enters the segment. Water temperature estimation is well correlated in the segment $\left(\operatorname{RMSE}=2.37^{\circ} \mathrm{C}, \mathrm{r}^{2}=0.83\right)$. 


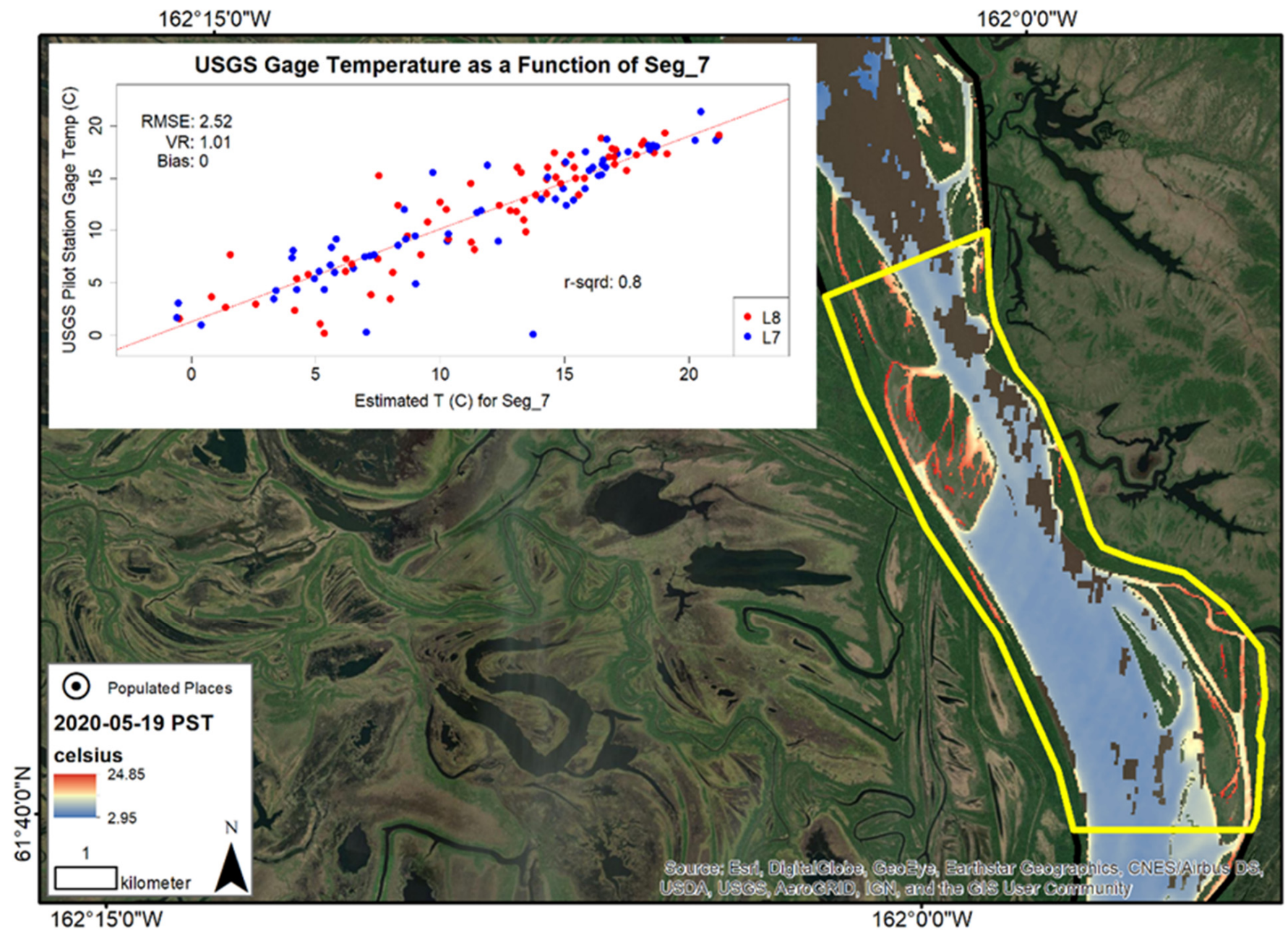

Figure A5. Segment 7 is slightly divided into small sloughs at both the beginning and end of the river segment. The sloughs appear as warmer surface temperatures due to shallow water depths. The eastern shore of the river is rolling uplands of the Ilivit Mountains divided by creeks and branching backwaters that contribute to the Yukon River. These water sources do not appear to influence the overall temperature of the river, as correlation with measured water temperature is good (RMSE $\left.=2.52{ }^{\circ} \mathrm{C}, \mathrm{r}^{2}=0.80\right)$ and similar to that of upstream river segments. Wetlands that comprised abandoned channels, oxbows, and broad lakes lie to the west. 




Figure A6. Segment 8 of the Yukon River intercepts a large island (Arbor Island) mid-section with Wilson Creek Slough passing to the east and the majority of the Yukon passing to the west. Several smaller but permanent islands are present as indicated by complete and dense shrub/forest cover. Smaller islands may appear at low stage. Two large NoData gaps happen to occupy the segment. The Ilivit Mountains rise on the east side of the river, while wetlands occupy the west side. This segment has slightly lower water temperature correlation than preceding river segments although it is still good overall $\left(\mathrm{RMSE}=2.71^{\circ} \mathrm{C}, \mathrm{r}^{2}=0.78\right)$. 




Figure A7. Segment 9 captures a large series of islands that split the Yukon River within this segment. The majority of the flow passes to the east as Poltes Slough while passing the community of Marshall at the terminal foothills of the Ilivit Mountains. Owl Creek also enters the Yukon River here. While the name suggests that Owl Creek flows into the Yukon, the heavy sediment content of Owl Creek and its numerous connections to the main stem of the Yukon as seen in high resolution imagery suggest the creek functioning more as a slough. For this reason, it is included in our analysis. Several large NoData gaps occur within the main stem and Poltes Slough. Like segment 8 , correlation with measured water temperature is slightly lower within this segment but is still relatively good $\left(\mathrm{RMSE}=2.62^{\circ} \mathrm{C}, \mathrm{r}^{2}=0.78\right)$. 


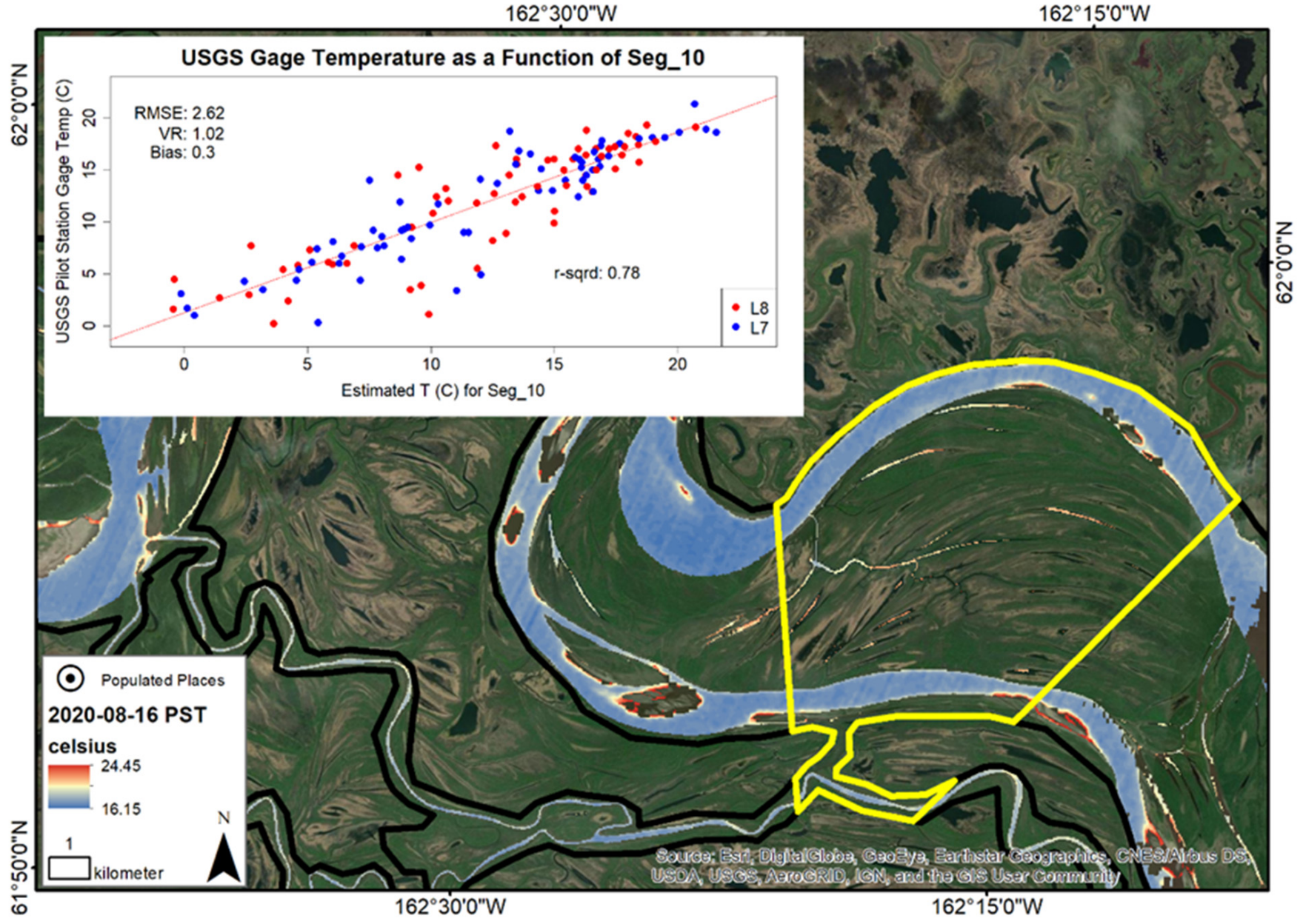

Figure A8. Within segment 10, the Yukon River is divided into three unique sections. Poltes Slough is the most northern one, while the main stem of the river is on the southern side of a large island, and a section of Owl Creek is furthest south. Wetlands surround all portions of this segment, given that the Yukon River leaves the last of the Ilivit Mountains in segment 9. The pST coverage for open water within this section is nearly $100 \%$ with no significant NoData gaps. At high stages, western portions of the large island can become inundated and present as warmer temperature water. These high water events occur during spring break-up. Depending on the proportion of the Yukon River that is also captured during these events, these inundated areas could significantly affect the average pST estimate for the segment. Correlation with measured water temperature is similar to all preceding river segments with an RMSE $=2.62{ }^{\circ} \mathrm{C}$ and $\mathrm{r}^{2}=0.78$. 
$162^{\circ} 45^{\prime} \mathrm{O}^{\prime \prime} \mathrm{W}$

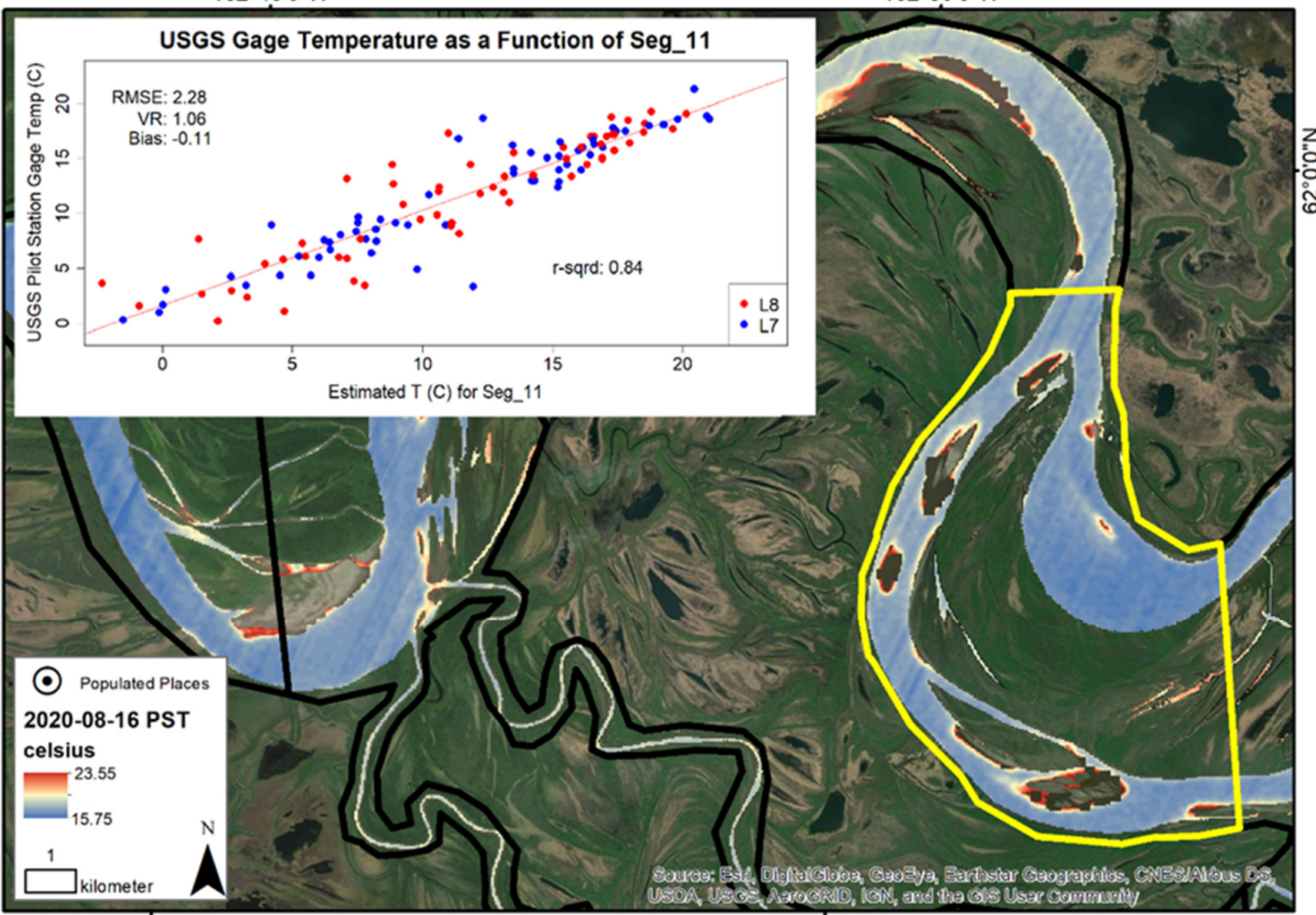

$162^{\circ} 45^{\prime} 0^{\prime \prime} \mathrm{W}$

$162^{\circ} 30^{\prime} 0^{\prime \prime} \mathrm{W}$

Figure A9. Within Segment 11, the Yukon transitions from two large channels to a single channel after Poltes Slough rejoins the main channel of the Yukon from the east. One small but permanent island lies within the main stem of the Yukon. Several smaller sandbars exist during low or moderate stages and are flooded at high stage. The pST coverage for open water within this section is nearly $100 \%$ with no significant NoData gaps. Wetlands surround all portions of this segment. Agreement between estimated water temperature and streamgage data is good $\left(\mathrm{RMSE}=2.28^{\circ} \mathrm{C}, \mathrm{r}^{2}=0.84\right)$. 


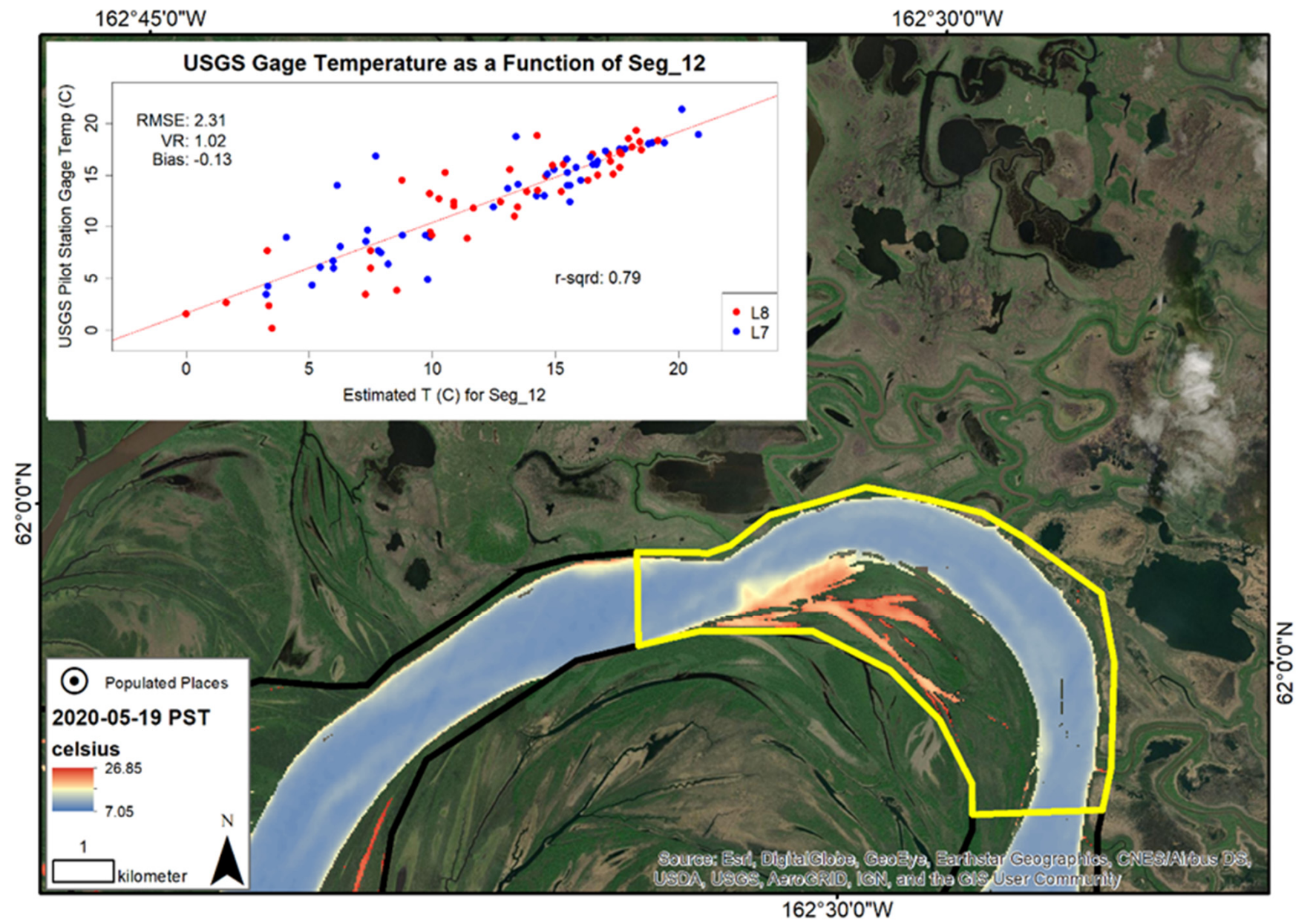

Figure A10. The Yukon River is confined to a single channel within segment 12. The channel occupies a large meander with low-lying wetlands to the north and an accreting point bar to the south that is also covered in wetlands. The accreting edge of the point bar is exposed as a sand and gravel bar when the river is not at high stages. At high stages, the sand/gravel bar is inundated as depicted in the scene above. A swath of backwater extends across the point bar at times as captured in the above scene. The backwaters appear as warmer inland water. Correlation between water temperature and the concurrently measured water temperature at Pilot Station is good $\left(\mathrm{RMSE}=2.31^{\circ} \mathrm{C}, \mathrm{r}^{2}=0.795\right)$. 


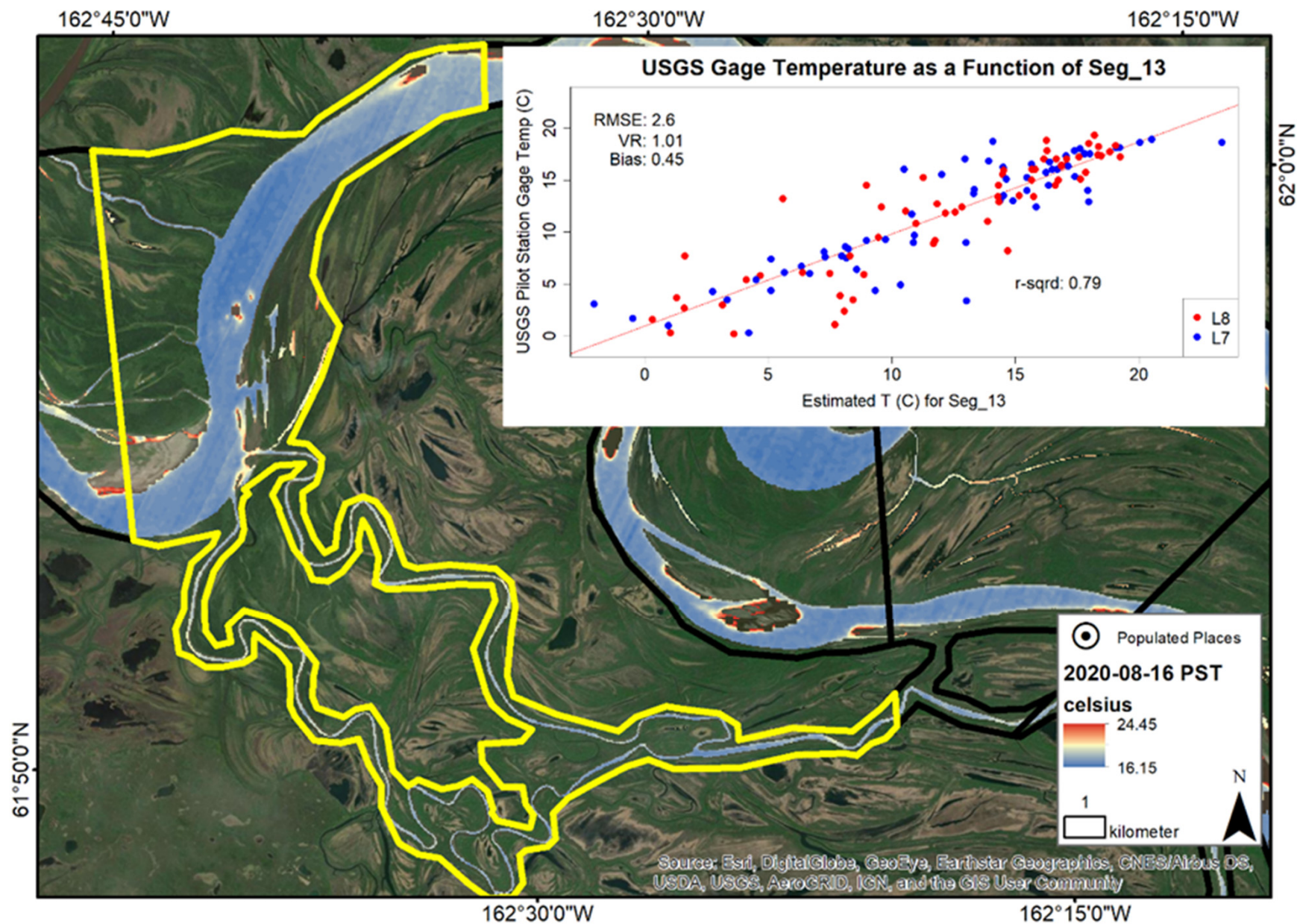

Figure A11. Segment 13 is unique in that it captures a portion of the northerly Center Slough and southerly Reindeer Creek River. We chose to include these extensions of the river due to their interconnectedness with the main flow as supported by the similar water temperature and sediment load that appears in these waterways. Despite a more unique distribution of water surface area, correlation between estimated (here) and measured (Pilot Station) water temperature remain good $\left(\right.$ RMSE $\left.=2.6{ }^{\circ} \mathrm{C}, \mathrm{r}^{2}=0.789\right)$. The pST coverage for open water within this section is $100 \%$ with no NoData gaps. Small sandbars are visible in the above scene. These bars grow in size as water levels drop and become inundated at high water stages. Wetlands surround all portions of this segment, and the Yukon River meanders around a large accreting point bar as it leaves the river segment. 




Figure A12. The Yukon River enters segment 14 flowing in a northwest direction, then making a hairpin turn before flowing southwest. The village of Pilot Station and the USGS gaging station are located in this segment. Pilot Station is located at a terminal end of the Adreafsky Mountains. Aside from this stretch of the river, the remaining shorelines are made up of lowlands and floodplains. The Chuilnak River enters the Yukon River upstream of Pilot Station. At high water stages, backwater features develop adjacent to the river as depicted in the above scene. The correlation between estimated and measured water temperature is good $\left(\mathrm{RMSE}=2.32{ }^{\circ} \mathrm{C}, \mathrm{r}^{2}=0.827\right)$. 




Figure A13. The Yukon River is divided into two main channels, and a minor slough within segment 15. Hills Slough is the most northern channel while the main stem of the Yukon passes to the south of Hills Island. A minor slough is the most southerly feature of the Yukon in this segment. It is identified both as Kashunuk Slough and Driftwood Slough on USGS quadrangle maps. The pST coverage is $100 \%$ within this section. At high water, channels and backwaters are flooded on Hill Island as depicted above. At lower stages, these water features are dry. Correlation between estimated and measured water temperature is good $\left(\mathrm{RMSE}=2.41{ }^{\circ} \mathrm{C}, \mathrm{r}^{2}=0.804\right)$. 


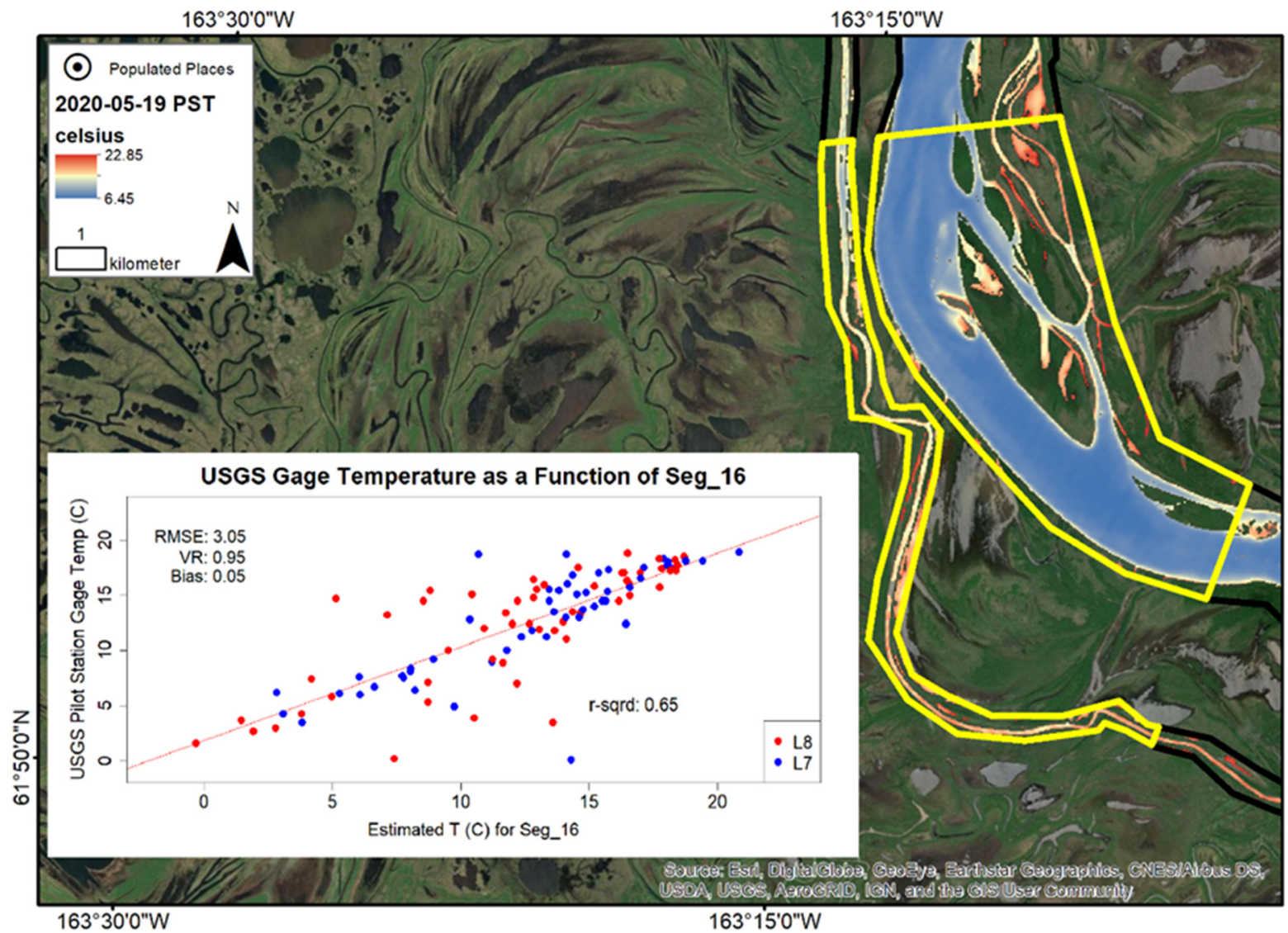

Figure A14. Segment 16 is the first segment fully downstream from the Pilot Station USGS streamgage. The river occupies a single channel interspersed with small islands. These islands have remained relatively undisturbed as indicated by dense shrub cover. Historically these islands were mapped as gravel bars. This suggests that the river channel is migrating to the west as it erodes into the long cut bank. Lowlands and wetlands surround the Yukon River. A portion of the segment is made up of Driftwood Slough as it courses along to the west of the Yukon River. Correlation between pST and measured water temperature is good (RMSE $=3.05{ }^{\circ} \mathrm{C}, \mathrm{r}^{2}=0.65$ ) but less than preceding river segments; pST coverage is $100 \%$ with no NoData gaps. 


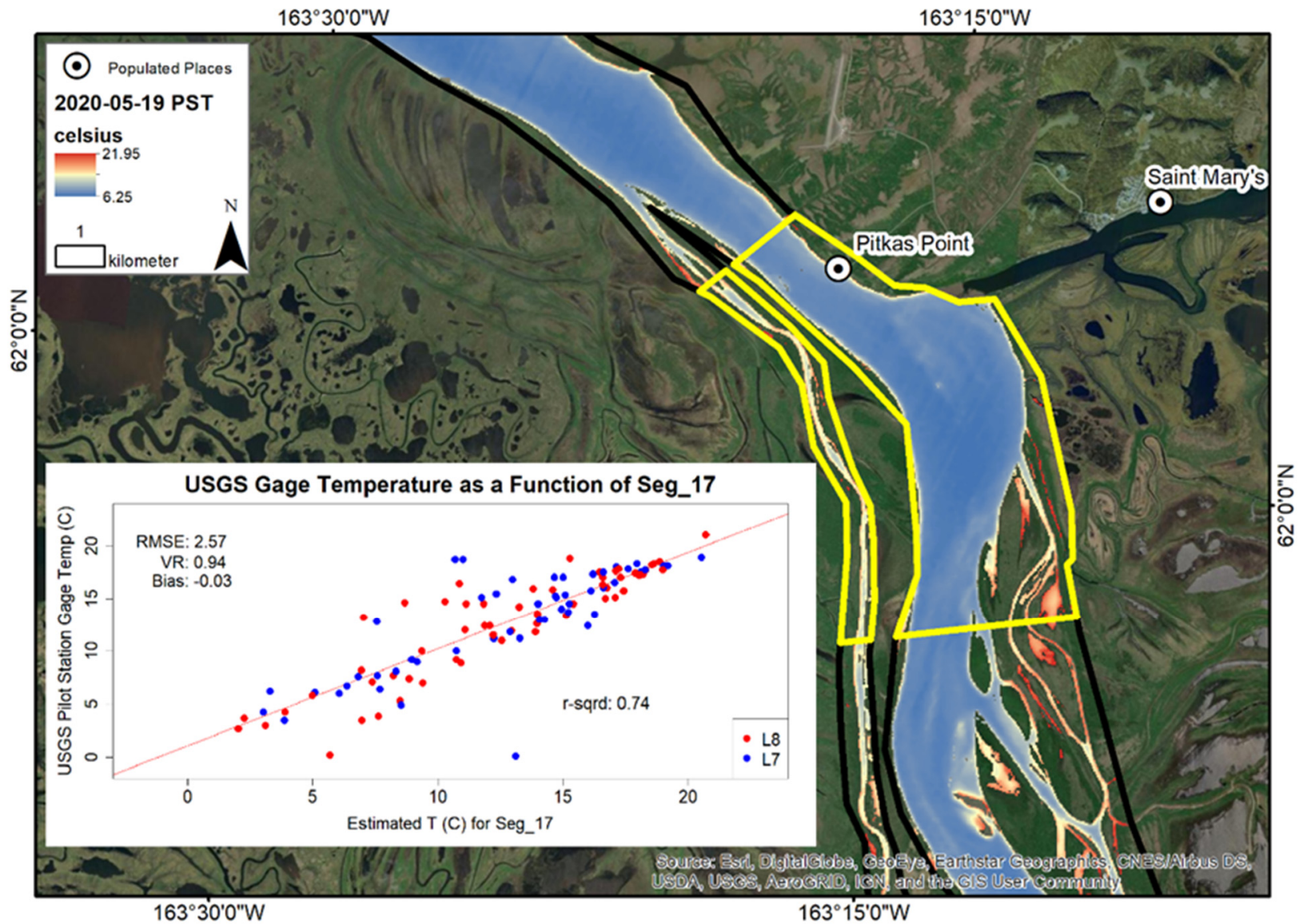

Figure A15. The river is contained to a single large channel and a meandering slough within segment 17. The river flows north leaving Goose Island, and then it bends slightly to the northwest after encountering another terminal extension of the Andreafsky Mountains. This is also where the Andreafsky River joins the Yukon River. The pST coverage is good with no NoData gaps. Correlations between water temperature datasets are good (RMSE $=2.57^{\circ} \mathrm{C}, \mathrm{r}^{2}=0.73$ ). 


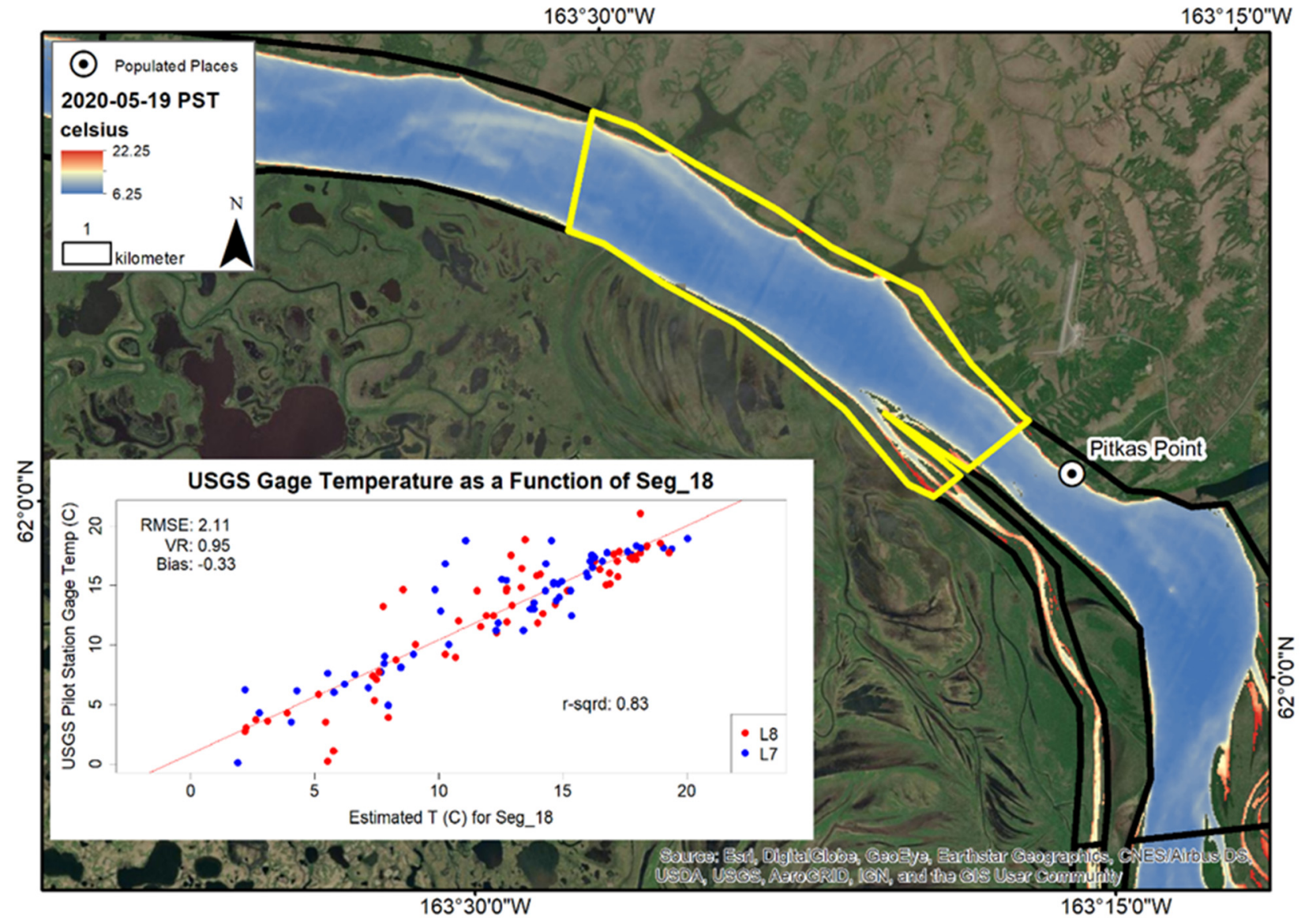

Figure A16. The entirety of the flow of the Yukon becomes constricted to a single channel within Segment 18 after the Driftwood slough. The northern shore of the river abuts the Andreafsky Mountains, while the southern shore comprises lowland sloughs, oxbows, and abandoned river channels. The pST coverage is $100 \%$ with no NoData gaps. Correlation with Pilot Station water temperature data is good $\left(\mathrm{RMSE}=2.11^{\circ} \mathrm{C}, \mathrm{r}^{2}=0.83\right)$. 


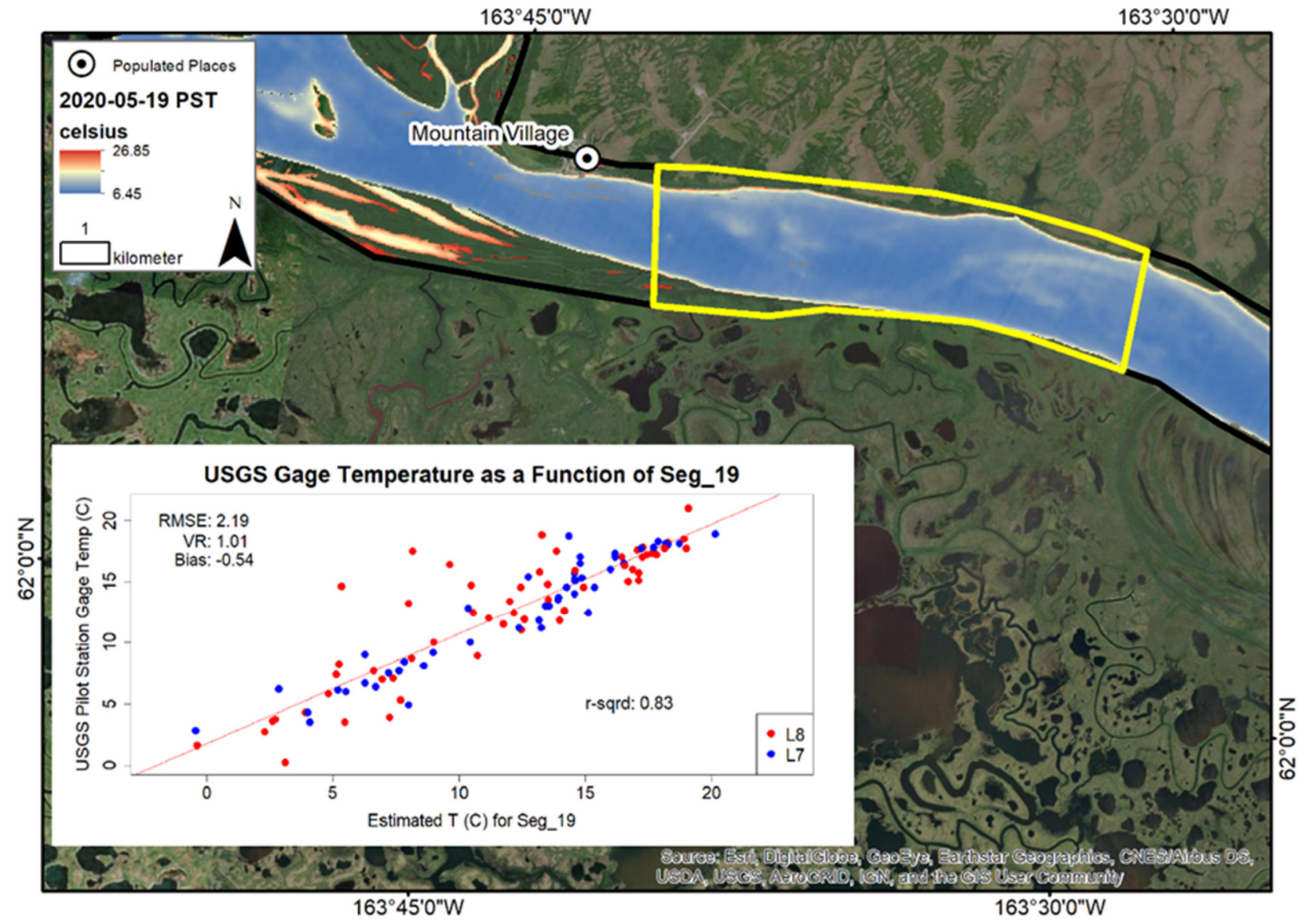

Figure A17. The Yukon River occupies a single channel roughly oriented east-west within Segment 19. Channel width is roughly consistent at a little over $2 \mathrm{~km}$ and bounded by the Andreafsky Mountains to the north and lowland flood plain to the south. The pST coverage is $100 \%$ with no NoData gaps. At high river stages, the channel is completely filled with water as depicted above. At lower stages, several sand and gravel bars are exposed in the mid-channel area. Correlation between water temperature datasets is good with $\mathrm{RMSE}=2.19^{\circ} \mathrm{C}$ and $\mathrm{r}^{2}=0.83$. 




Figure A18. Segment 20 is characterized by the division of the Yukon into two large channels and a number of sloughs. This is a result of the river losing contact with the Adreafsky Mountains. The community of Mountain Village falls within this segment. Multiple islands occur within this segment and produce warm water signatures. At lower stages, the size and number of exposed islands increases. Recently abandoned river channels also produce warm water signatures when river height is sufficient to inundate these areas as is depicted above. The pST coverage is $100 \%$ with no NoData gaps; however, correlation between water temperature datasets is lower in this segment (RMSE $=2.71{ }^{\circ} \mathrm{C}, \mathrm{r}^{2}=0.723$ ) compared to most upstream segments. 




Figure A19. The Yukon River is divided into multiple channels in segment 21. The main stem lies further west and flows through a long meander in a northerly direction. This main channel is divided by islands whose size fluctuates with river stage. To the east, a large slough (Patsy's Slough) meanders north. This slough is large enough to maintain the cooler water temperatures similar to those in the main stem. Furthest east is the Azacharum Slough. This slough has broader meanders and warmer estimated water temperatures. Other minor sloughs, channels, and surface water are featured in this segment during high river stages. The pST is $100 \%$ with no NoData gaps. This segment features the poorest correlation of all river segments $\left(\mathrm{RMSE}=3.44^{\circ} \mathrm{C}, \mathrm{r}^{2}=0.591\right)$. 


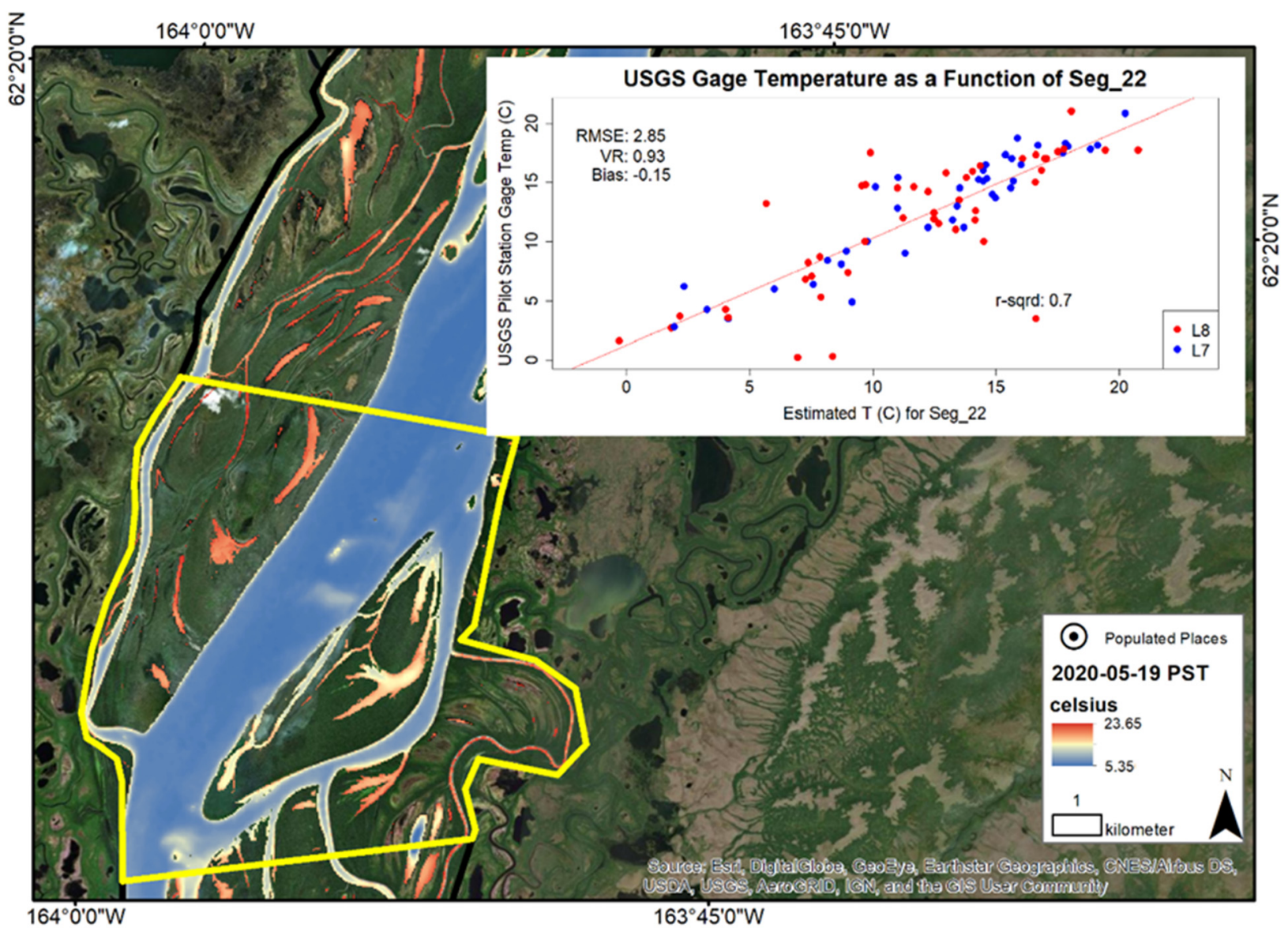

Figure A20. Segment 22 captures sloughs rejoining the Yukon River on the east bank as well as the large Tunurokpak Channel leaving the western bank. This channel maintains water temperatures similar to those in the main stem. Another unnamed channel flows around a large forested island, which at high river stages also contains warm backwater features. In the scene above, slightly warmer water in the main channel reveal where sand and gravel bars emerge during intermediate and low flow stages. Both shores of the river are made up of lowland flood plains featuring lakes and abandoned channels. The pST is $100 \%$ with no NoData gaps. Correlation between pST estimates and Pilot Station recorded data is $\mathrm{r}^{2}=0.704$ which is slightly less than the upper levels of correlation seen elsewhere along the river. Agreement remained good with $\mathrm{RMSE}=2.85^{\circ} \mathrm{C}$. This is the third highest RMSE from all river segments. 


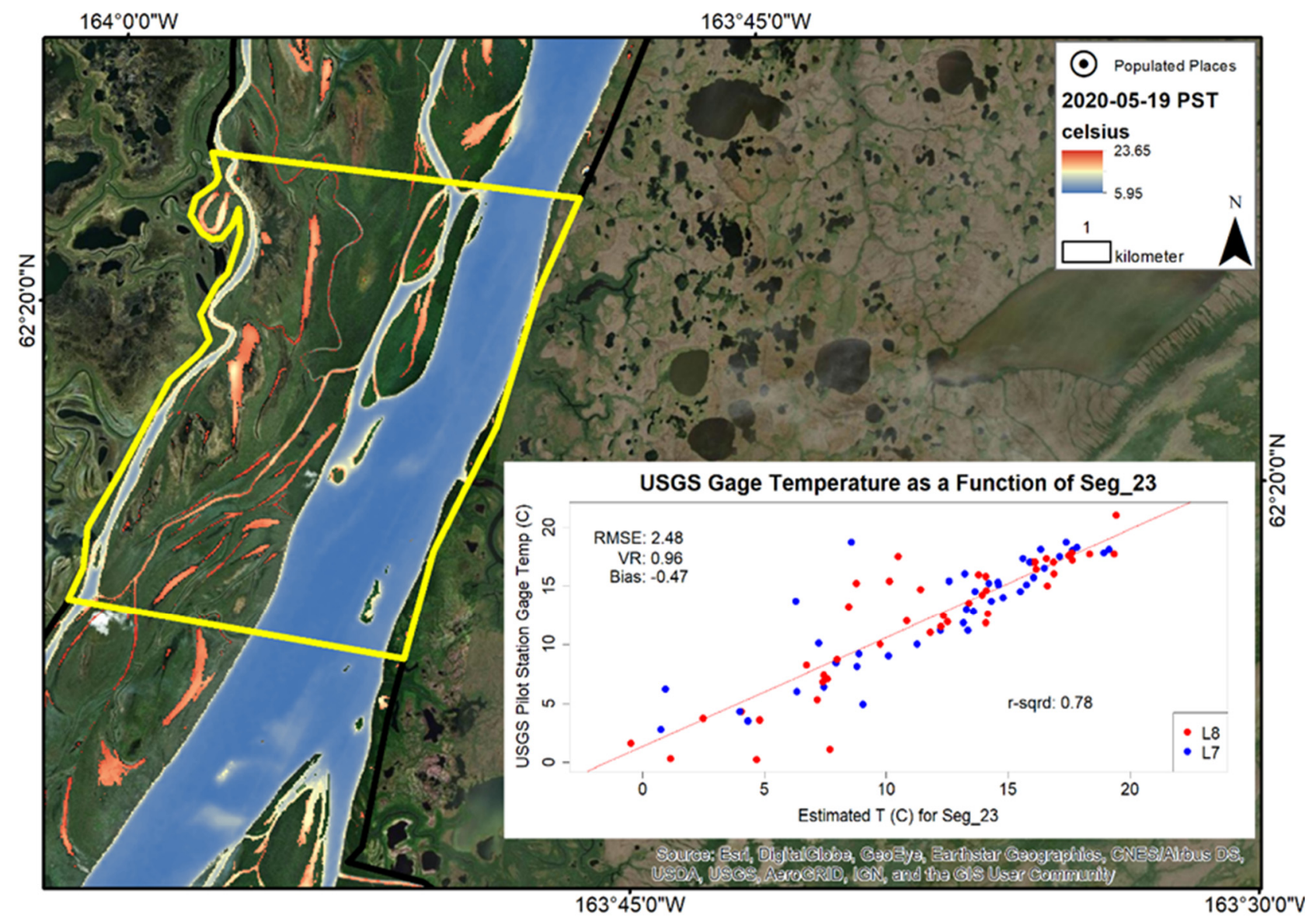

Figure A21. In segment 23, the Yukon River flows in a north northeast direction. The east bank of the river abuts low hills and slight uplands, while the west shore is broken by islands, small sloughs, and channels. The western extreme of the Yukon lies in the Tunurokpak Channel. While this channel is estimated to have cool water temperatures, smaller unnamed sloughs, backwaters, and surface water features can occur with warmer estimated water temperatures. River stage influences the number and size of these features as well as the number and size of islands that exist in the main channel. The pST is $100 \%$ with no NoData gaps. Correlation between pST estimates and Pilot Station recordings is good $\left(\right.$ RMSE $=2.48, \mathrm{r}^{2}=0.78$. 


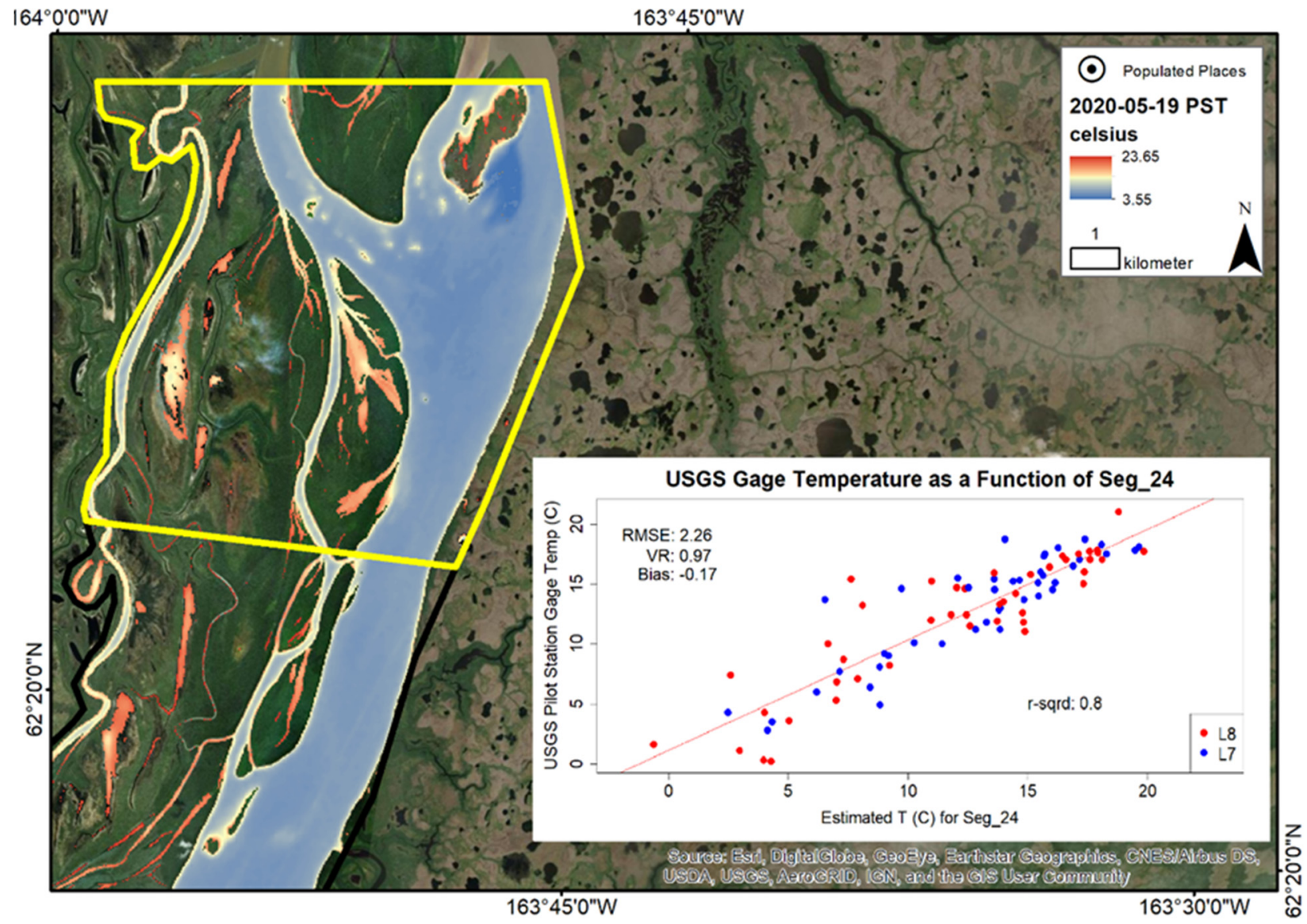

Figure A22. Segment 24 captures the Yukon River dividing into two large channels in addition to a portion of river continuing to flow within the Tunurokpak Channel. The east bank of the river abuts low hills and slight uplands while the west shore is broken by islands, small sloughs, and channels. The western extreme of the Yukon lies in the Tunurokpak Channel. Water temperatures are estimated to have cool water temperatures similar to those of the main stem. A large channel isolates a large unnamed island that, at high river stage, hosts a number of backwater features. At high stage flow, the Yukon is inundated bank to bank aside from large forested islands. At lower stages, numerous sand and gravel bars emerge upstream of these islands. Several small warm water features reveal these submerged islands in the scene above. This is the final $10 \mathrm{~km}$ stretch of river captured in our analysis. Similar to the preceding segment, pST is $100 \%$ with no NoData gaps. Despite this part being the river segment furthest downstream of the Pilot Station gage, correlation between pST estimates and the Pilot Station recordings is consistent with the majority of other river segments $\left(\mathrm{RMSE}=2.26^{\circ} \mathrm{C}\right.$, $\left.r^{2}=0.797\right)$. 


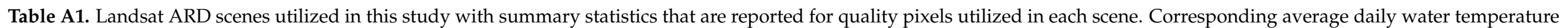
recorded at the USGS Pilot Station streamgage are listed for comparison.

\begin{tabular}{|c|c|c|c|c|c|c|c|c|c|}
\hline \multirow[b]{2}{*}{ Date } & \multirow[b]{2}{*}{ Landsat ARD Product ID } & \multirow[b]{2}{*}{ Pixel Count } & \multirow[b]{2}{*}{ Area $\mathbf{k m}^{2}$} & \multicolumn{5}{|c|}{ Provisional Surface Temperature ${ }^{\circ} \mathrm{C}$} & \multirow[b]{2}{*}{ USGS Streamgage ${ }^{\circ} \mathrm{C}$} \\
\hline & & & & Min & Max & Range & Mean & STD & \\
\hline $5 / 21 / 2014$ & LC08_AK_002007_20140521_20190504_C01_V01 & 4059 & 3.7 & 5.45 & 16.15 & 10.7 & 7.6 & 2.3 & 5.5 \\
\hline $6 / 4 / 2014$ & LC08_AK_002007_20140604_20190504_C01_V01 & 344,827 & 310.3 & -0.95 & 24.85 & 25.8 & 10.2 & 2.9 & 9 \\
\hline $6 / 5 / 2014$ & LE07_AK_002007_20140605_20190504_C01_V01 & 1427 & 1.3 & 2.75 & 16.25 & 13.5 & 7.5 & 2.6 & 10 \\
\hline $6 / 6 / 2014$ & LC08_AK_002007_20140606_20190504_C01_V01 & 4522 & 4.1 & 12.45 & 22.35 & 9.9 & 13.6 & 1.3 & 10 \\
\hline $6 / 19 / 2014$ & LE07_AK_002007_20140619_20190208_C01_V01 & 141,950 & 127.8 & 11.65 & 23.95 & 12.3 & 13.7 & 1.2 & 13.5 \\
\hline $6 / 20 / 2014$ & ILC08_AK_002007_20140620_20190504_C01_V01 & 389,404 & 350.5 & 13.45 & 29.25 & 15.8 & 15.1 & 1.4 & 14 \\
\hline $6 / 21 / 2014$ & LE07_AK_002007_20140621_20190504_C01_V01 & 149,300 & 134.4 & 11.65 & 43.05 & 31.4 & 16.1 & 1.8 & 14.5 \\
\hline $6 / 22 / 2014$ & LC08_AK_002007_20140622_20190504_C01_V01 & 3436 & 3.1 & 14.25 & 29.85 & 15.6 & 16.9 & 2.0 & 15 \\
\hline $6 / 27 / 2014$ & LC08_AK_002007_20140627_20190504_C01_V01 & 193,873 & 174.5 & 15.75 & 29.35 & 13.6 & 17.0 & 1.0 & 16 \\
\hline $6 / 30 / 2014$ & LE07_AK_002007_20140630_20190504_C01_V01 & 56,495 & 50.8 & 14.25 & 31.05 & 16.8 & 16.2 & 1.1 & 16 \\
\hline $7 / 5 / 2014$ & LE07_AK_002007_20140705_20190504_C01_V01 & 138,805 & 124.9 & 13.95 & 37.35 & 23.4 & 16.3 & 1.3 & 17 \\
\hline $7 / 6 / 2014$ & LC08_AK_002007_20140706_20190504_C01_V01 & 324,732 & 292.3 & 7.65 & 38.95 & 31.3 & 17.7 & 1.5 & 17.5 \\
\hline $7 / 29 / 2014$ & LC08_AK_002007_20140729_20190504_C01_V01 & 198,991 & 179.1 & 13.35 & 27.75 & 14.4 & 15.6 & 1.2 & 14.5 \\
\hline $7 / 30 / 2014$ & LE07_AK_002007_20140730_20190504_C01_V01 & 79,702 & 71.7 & 4.55 & 25.55 & 21 & 12.5 & 2.0 & 14.5 \\
\hline $8 / 7 / 2014$ & LC08_AK_002007_20140807_20190505_C01_V01 & 1 & 0.001 & 6.55 & 6.55 & 0 & 6.6 & 0.0 & 16 \\
\hline $8 / 9 / 2014$ & LC08_AK_002007_20140809_20190504_C01_V01 & 5929 & 5.3 & 9.45 & 18.55 & 9.1 & 14.4 & 1.3 & 16 \\
\hline $8 / 14 / 2014$ & LC08_AK_002007_20140814_20190504_C01_V01 & 36,458 & 32.8 & 8.45 & 22.25 & 13.8 & 16.0 & 1.4 & 17 \\
\hline $8 / 15 / 2014$ & LE07_AK_002007_20140815_20190504_C01_V01 & 55,910 & 50.3 & 7.45 & 29.35 & 21.9 & 16.9 & 1.6 & 17 \\
\hline $8 / 16 / 2014$ & LC08_AK_002007_20140816_20190504_C01_V01 & 34,561 & 31.1 & 10.95 & 20.75 & 9.8 & 16.2 & 0.9 & 17 \\
\hline $8 / 17 / 2014$ & LE07_AK_002007_20140817_20190504_C01_V01 & 5031 & 4.5 & 12.05 & 23.05 & 11 & 16.1 & 1.1 & 17 \\
\hline $8 / 30 / 2014$ & LC08_AK_002007_20140830_20190504_C01_V01 & 104,275 & 93.8 & 9.95 & 21.05 & 11.1 & 13.9 & 0.6 & 14.5 \\
\hline $8 / 31 / 2014$ & LE07_AK_002007_20140831_20190503_C01_V01 & 2312 & 2.1 & 5.55 & 13.55 & 8 & 9.8 & 1.3 & 14.5 \\
\hline $9 / 15 / 2014$ & LC08_AK_002007_20140915_20190504_C01_V01 & 31,264 & 28.1 & 8.25 & 18.95 & 10.7 & 11.1 & 1.9 & 10 \\
\hline
\end{tabular}


Table A1. Cont.

\begin{tabular}{|c|c|c|c|c|c|c|c|c|c|}
\hline \multirow[b]{2}{*}{ Date } & \multirow[b]{2}{*}{ Landsat ARD Product ID } & \multirow[b]{2}{*}{ Pixel Count } & \multirow[b]{2}{*}{ Area $\mathbf{k m}^{2}$} & \multicolumn{5}{|c|}{ Provisional Surface Temperature ${ }^{\circ} \mathrm{C}$} & \multirow[b]{2}{*}{ USGS Streamgage ${ }^{\circ} \mathrm{C}$} \\
\hline & & & & Min & Max & Range & Mean & STD & \\
\hline $9 / 16 / 2014$ & LE07_AK_002007_20140916_20190208_C01_V01 & 21,721 & 19.5 & 7.55 & 17.25 & 9.7 & 9.7 & 1.4 & 9.5 \\
\hline $10 / 1 / 2014$ & LC08_AK_002007_20141001_20190503_C01_V01 & 164,602 & 148.1 & 6.25 & 13.95 & 7.7 & 7.5 & 0.8 & 7.1 \\
\hline $10 / 3 / 2014$ & LC08_AK_002007_20141003_20190503_C01_V01 & 167,863 & 151.1 & 1.95 & 10.85 & 8.9 & 5.2 & 0.5 & 6.1 \\
\hline $10 / 4 / 2014$ & LE07_AK_002007_20141004_20190503_C01_V01 & 33,394 & 30.1 & -2.45 & 9.15 & 11.6 & 4.0 & 1.1 & 5.4 \\
\hline $5 / 15 / 2015$ & LC08_AK_002007_20150515_20190502_C01_V01 & 8886 & 8.0 & -6.05 & 17.05 & 23.1 & 2.0 & 3.1 & 0.1 \\
\hline $5 / 24 / 2015$ & LC08_AK_002007_20150524_20190607_C01_V01 & 3319 & 3.0 & 3.05 & 16.75 & 13.7 & 6.7 & 1.4 & 5.9 \\
\hline $5 / 29 / 2015$ & LCC08_AK_002007_20150529_20190502_C01_V01 & 38,728 & 34.9 & 4.35 & 22.45 & 18.1 & 9.6 & 3.0 & 10.1 \\
\hline $5 / 30 / 2015$ & LE07_AK_002007_20150530_20190208_C01_V01 & 183,585 & 165.2 & 7.95 & 33.35 & 25.4 & 13.2 & 2.3 & 11 \\
\hline $5 / 31 / 2015$ & LC08_AK_002007_20150531_20190502_C01_V01 & 18,948 & 17.1 & 2.65 & 20.95 & 18.3 & 11.7 & 2.2 & 11.9 \\
\hline $6 / 1 / 2015$ & LE07_AK_002007_20150601_20181206_C01_V01 & 8362 & 7.5 & 4.15 & 17.15 & 13 & 9.7 & 1.7 & 12.7 \\
\hline $6 / 6 / 2015$ & LE07_AK_002007_20150606_20190502_C01_V01 & 653 & 0.6 & 4.45 & 10.45 & 6 & 6.8 & 1.0 & 13.7 \\
\hline $6 / 15 / 2015$ & LE07_AK_002007_20150615_20190502_C01_V01 & 335,071 & 301.6 & 11.25 & 25.25 & 14 & 13.9 & 1.4 & 13 \\
\hline $6 / 16 / 2015$ & LC08_AK_002007_20150616_20190502_C01_V01 & 329,362 & 296.4 & 8.85 & 26.85 & 18 & 15.3 & 1.7 & 13.4 \\
\hline $6 / 17 / 2015$ & ILE07_AK_002007_20150617_20181206_C01_V01 & 90,172 & 81.2 & 13.75 & 30.15 & 16.4 & 16.1 & 1.8 & 14 \\
\hline $6 / 22 / 2015$ & LE07_AK_002007_20150622_20190502_C01_V01 & 80,318 & 72.3 & 5.85 & 25.45 & 19.6 & 14.6 & 3.1 & 17.5 \\
\hline $6 / 23 / 2015$ & LC08_AK_002007_20150623_20190502_C01_V01 & 211,305 & 190.2 & 9.85 & 30.85 & 21 & 19.1 & 0.9 & 18.1 \\
\hline $6 / 24 / 2015$ & LE07_AK_002007_20150624_20190502_C01_V01 & 182,729 & 164.5 & 16.35 & 29.35 & 13 & 18.4 & 0.9 & 18.5 \\
\hline $6 / 25 / 2015$ & LC08_AK_002007_20150625_20190502_C01_V01 & 108,263 & 97.4 & 19.25 & 29.05 & 9.8 & 20.3 & 0.8 & 18.6 \\
\hline $7 / 27 / 2015$ & LCC08_AK_002007_20150727_20190501_C01_V01 & 1788 & 1.6 & 15.85 & 23.55 & 7.7 & 17.3 & 0.9 & 16.4 \\
\hline $8 / 2 / 2015$ & LE07_AK_002007_20150802_20190501_C01_V01 & 132,993 & 119.7 & 12.75 & 30.05 & 17.3 & 16.8 & 1.0 & 17.3 \\
\hline $8 / 3 / 2015$ & LC08_AK_002007_20150803_20190501_C01_V01 & 251,387 & 226.2 & 15.75 & 30.05 & 14.3 & 18.4 & 0.8 & 17.4 \\
\hline $8 / 4 / 2015$ & LE07_AK_002007_20150804_20181206_C01_V01 & 75,918 & 68.3 & 16.25 & 31.35 & 15.1 & 17.8 & 1.0 & 17.5 \\
\hline
\end{tabular}


Table A1. Cont.

\begin{tabular}{|c|c|c|c|c|c|c|c|c|c|}
\hline \multirow[b]{2}{*}{ Date } & \multirow[b]{2}{*}{ Landsat ARD Product ID } & \multirow[b]{2}{*}{ Pixel Count } & \multirow[b]{2}{*}{ Area km² } & \multicolumn{5}{|c|}{ Provisional Surface Temperature ${ }^{\circ} \mathrm{C}$} & \multirow[b]{2}{*}{ USGS Streamgage ${ }^{\circ} \mathrm{C}$} \\
\hline & & & & Min & Max & Range & Mean & STD & \\
\hline $9 / 11 / 2015$ & LC08_AK_002007_20150911_20190501_C01_V01 & 83,123 & 74.8 & 3.15 & 12.25 & 9.1 & 9.5 & 0.7 & 10 \\
\hline $9 / 21 / 2015$ & LE07_AK_002007_20150921_20190501_C01_V01 & 11,730 & 10.6 & 3.05 & 12.45 & 9.4 & 5.9 & 0.8 & 7.3 \\
\hline $9 / 26 / 2015$ & LE07_AK_002007_20150926_20190501_C01_V01 & 55,449 & 49.9 & 0.25 & 7.95 & 7.7 & 2.8 & 0.8 & 6.2 \\
\hline $9 / 28 / 2015$ & LE07_AK_002007_20150928_20190501_C01_V01 & 60,172 & 54.2 & -7.55 & 8.15 & 15.7 & 4.8 & 0.7 & 5.8 \\
\hline $9 / 29 / 2015$ & LC08_AK_002007_20150929_20190501_C01_V01 & 15,436 & 13.9 & 1.95 & 7.95 & 6 & 5.1 & 0.5 & 5.4 \\
\hline $10 / 5 / 2015$ & LE07_AK_002007_20151005_20190207_C01_V01 & 6 & 0.005 & -1.15 & 0.35 & 1.5 & -0.4 & 0.4 & 4.5 \\
\hline $10 / 7 / 2015$ & LE07_AK_002007_20151007_20181206_C01_V01 & 70,323 & 63.3 & 2.05 & 11.05 & 9 & 4.3 & 1.2 & 4.4 \\
\hline $10 / 14 / 2015$ & LE07_AK_002007_20151014_20190501_C01_V01 & 163,062 & 146.8 & 0.15 & 11.85 & 11.7 & 2.7 & 1.0 & 3 \\
\hline $10 / 15 / 2015$ & LC08_AK_002007_20151015_20190501_C01_V01 & 46,883 & 42.2 & 2.25 & 8.75 & 6.5 & 3.3 & 0.6 & 2.7 \\
\hline $10 / 21 / 2015$ & LE07_AK_002007_20151021_20190501_C01_V01 & 103,946 & 93.6 & -3.45 & 3.45 & 6.9 & -0.3 & 0.9 & 1.6 \\
\hline $10 / 23 / 2015$ & LE07_AK_002007_20151023_20181210_C01_V01 & 70,903 & 63.8 & -1.35 & 5.65 & 7 & 0.3 & 0.8 & 1 \\
\hline $5 / 16 / 2016$ & LE07_AK_002007_20160516_20181211_C01_V01 & 330,368 & 297.3 & 1.45 & 28.85 & 27.4 & 7.9 & 3.0 & 6.4 \\
\hline $5 / 17 / 2016$ & LC08_AK_002007_20160517_20190430_C01_V01 & 19,028 & 17.1 & -0.85 & 26.95 & 27.8 & 9.9 & 3.8 & 7 \\
\hline $5 / 26 / 2016$ & ILC08_AK_002007_20160526_20190607_C01_V01 & 134,738 & 121.3 & 5.85 & 23.05 & 17.2 & 10.9 & 1.3 & 9 \\
\hline $5 / 31 / 2016$ & LC08_AK_002007_20160531_20190430_C01_V01 & 208,830 & 187.9 & 12.35 & 30.55 & 18.2 & 14.3 & 2.0 & 11.8 \\
\hline $6 / 2 / 2016$ & ILC08_AK_002007_20160602_20181211_C01_V01 & 336,772 & 303.1 & 12.65 & 28.35 & 15.7 & 14.5 & 1.3 & 13 \\
\hline $6 / 16 / 2016$ & LC08_AK_002007_20160616_20190430_C01_V01 & 47,095 & 42.4 & 3.05 & 24.25 & 21.2 & 11.1 & 3.2 & 14.6 \\
\hline $7 / 2 / 2016$ & LC08_AK_002007_20160702_20181210_C01_V01 & 24,564 & 22.1 & 6.75 & 24.05 & 17.3 & 13.5 & 2.4 & 18.7 \\
\hline $7 / 4 / 2016$ & LCC08_AK_002007_20160704_20181211_C01_V01 & 153,688 & 138.3 & 5.55 & 28.95 & 23.4 & 16.5 & 2.2 & 18.8 \\
\hline $7 / 10 / 2016$ & LE07_AK_002007_20160710_20190430_C01_V01 & 121,659 & 109.5 & 15.05 & 24.65 & 9.6 & 17.9 & 0.7 & 18.3 \\
\hline $7 / 12 / 2016$ & LE07_AK_002007_20160712_20181209_C01_V01 & 237,587 & 213.8 & 16.15 & 33.95 & 17.8 & 18.4 & 1.3 & 18.2 \\
\hline $7 / 13 / 2016$ & LC08_AK_002007_20160713_20190430_C01_V01 & 110,388 & 99.3 & 19.75 & 36.35 & 16.6 & 21.4 & 1.4 & 18.6 \\
\hline
\end{tabular}


Table A1. Cont.

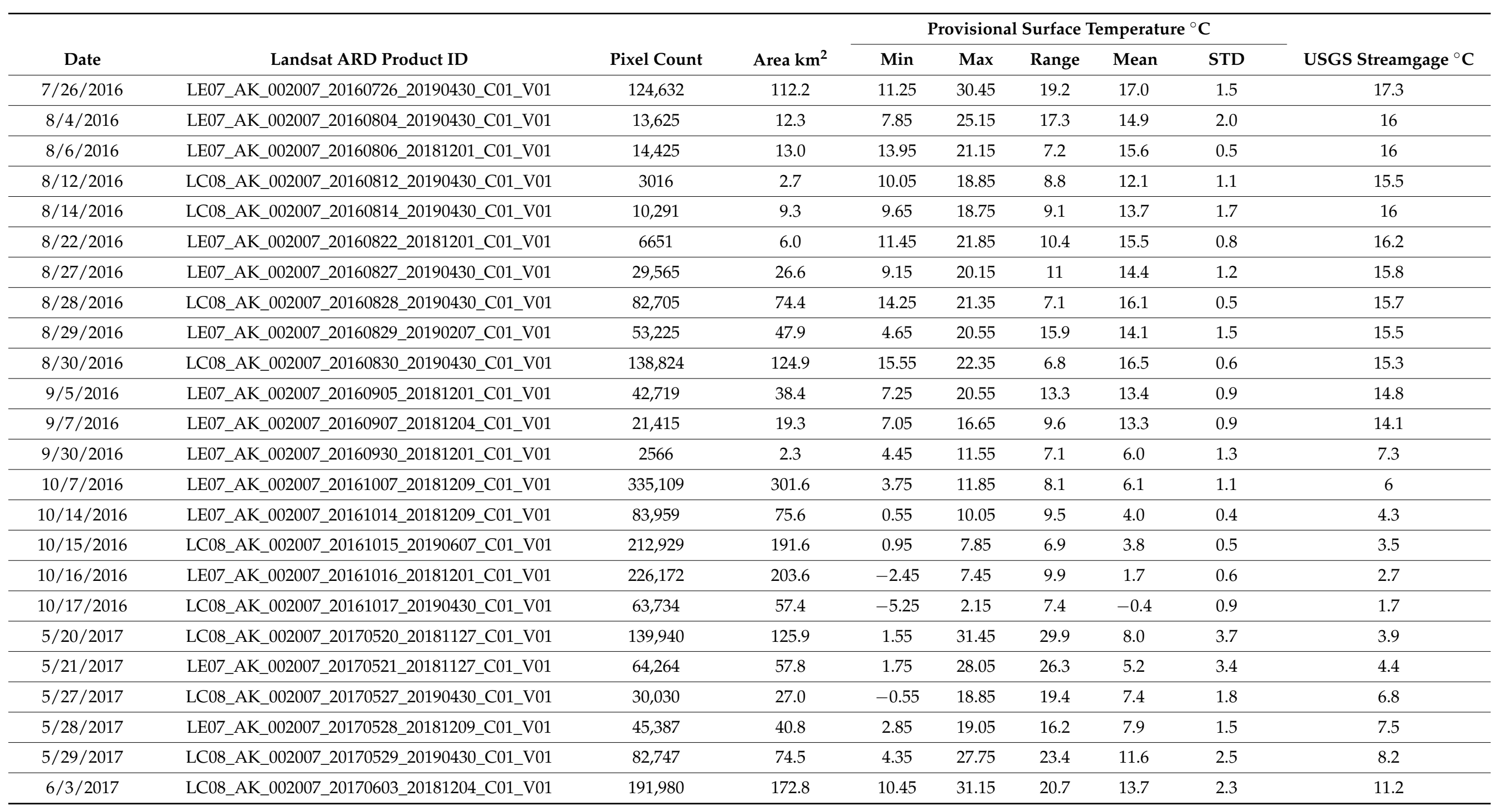


Table A1. Cont.

\begin{tabular}{|c|c|c|c|c|c|c|c|c|c|}
\hline \multirow[b]{2}{*}{ Date } & \multirow[b]{2}{*}{ Landsat ARD Product ID } & \multirow[b]{2}{*}{ Pixel Count } & \multirow[b]{2}{*}{ Area $\mathbf{k m}^{2}$} & \multicolumn{5}{|c|}{ Provisional Surface Temperature ${ }^{\circ} \mathrm{C}$} & \multirow[b]{2}{*}{ USGS Streamgage ${ }^{\circ}$} \\
\hline & & & & Min & Max & Range & Mean & STD & \\
\hline $6 / 4 / 2017$ & LE07_AK_002007_20170604_20181209_C01_V01 & 310,146 & 279.1 & 6.85 & 36.05 & 29.2 & 12.9 & 2.5 & 11.9 \\
\hline $6 / 6 / 2017$ & LE07_AK_002007_20170606_20181209_C01_V01 & 1448 & 1.3 & 9.65 & 18.35 & 8.7 & 12.9 & 1.7 & 12.9 \\
\hline $6 / 11 / 2017$ & LE07_AK_002007_20170611_20190430_C01_V01 & 2 & 0.002 & 10.65 & 12.85 & 2.2 & 11.8 & 1.1 & 15.1 \\
\hline $6 / 12 / 2017$ & LC08_AK_002007_20170612_20190430_C01_V01 & 10,069 & 9.1 & 6.95 & 18.25 & 11.3 & 10.9 & 2.1 & 15.2 \\
\hline $6 / 22 / 2017$ & LE07_AK_002007_20170622_20181127_C01_V01 & 26 & 0.023 & 3.25 & 8.15 & 4.9 & 5.5 & 1.3 & 16 \\
\hline $8 / 6 / 2017$ & LC08_AK_002007_20170806_20181203_C01_V01 & 153,828 & 138.4 & 16.55 & 30.05 & 13.5 & 19.2 & 1.4 & 17.7 \\
\hline $8 / 7 / 2017$ & LE07_AK_002007_20170807_20181204_C01_V01 & 137,312 & 123.6 & 14.35 & 35.15 & 20.8 & 18.6 & 1.6 & 18.1 \\
\hline $8 / 17 / 2017$ & LC08_AK_002007_20170817_20190430_C01_V01 & 40,004 & 36.0 & 10.75 & 23.15 & 12.4 & 17.5 & 0.9 & 16.4 \\
\hline $8 / 23 / 2017$ & LE07_AK_002007_20170823_20181130_C01_V01 & 879 & 0.8 & 7.65 & 12.65 & 5 & 10.5 & 1.0 & 14.6 \\
\hline $8 / 31 / 2017$ & LC08_AK_002007_20170831_20190430_C01_V01 & 16,753 & 15.1 & 4.05 & 15.55 & 11.5 & 11.5 & 1.1 & 12.4 \\
\hline 9/26/2017 & LE07_AK_002007_20170926_20181130_C01_V01 & 88,872 & 80.0 & 5.95 & 14.25 & 8.3 & 8.2 & 0.7 & 8.6 \\
\hline $10 / 18 / 2017$ & LC08_AK_002007_20171018_20190430_C01_V01 & 140,868 & 126.8 & -2.15 & 5.85 & 8 & 3.2 & 1.0 & 4.3 \\
\hline $10 / 19 / 2017$ & LE07_AK_002007_20171019_20181130_C01_V01 & 92,923 & 83.6 & -3.65 & 7.15 & 10.8 & 2.3 & 1.0 & 3.7 \\
\hline $10 / 20 / 2017$ & LC08_AK_002007_20171020_20190430_C01_V01 & 26,125 & 23.5 & -3.65 & 2.85 & 6.5 & 0.5 & 1.1 & 3.1 \\
\hline $5 / 23 / 2018$ & LC08_AK_002007_20180523_20190615_C01_V01 & 135,115 & 121.6 & 3.95 & 28.35 & 24.4 & 8.4 & 3.7 & 3.5 \\
\hline $5 / 31 / 2018$ & LE07_AK_002007_20180531_20190615_C01_V01 & 21,157 & 19.0 & 2.95 & 18.85 & 15.9 & 7.9 & 1.6 & 9.2 \\
\hline $6 / 1 / 2018$ & LC08_AK_002007_20180601_20190615_C01_V01 & 12,707 & 11.4 & 8.35 & 23.55 & 15.2 & 13.6 & 2.9 & 9.9 \\
\hline $6 / 6 / 2018$ & LC08_AK_002007_20180606_20190615_C01_V01 & 207,676 & 186.9 & 4.35 & 23.85 & 19.5 & 11.6 & 2.3 & 12.8 \\
\hline $6 / 7 / 2018$ & LE07_AK_002007_20180607_20190615_C01_V01 & 281,730 & 253.6 & 0.85 & 17.85 & 17 & 7.3 & 2.1 & 13.2 \\
\hline $6 / 8 / 2018$ & LC08_AK_002007_20180608_20190617_C01_V01 & 55,907 & 50.3 & 12.05 & 21.05 & 9 & 13.9 & 0.8 & 13.5 \\
\hline $6 / 9 / 2018$ & LE07_AK_002007_20180609_20190615_C01_V01 & 120,285 & 108.3 & 12.05 & 23.25 & 11.2 & 14.4 & 1.1 & 13.5 \\
\hline $6 / 14 / 2018$ & LE07_AK_002007_20180614_20190615_C01_V01 & 143,239 & 128.9 & 13.25 & 25.15 & 11.9 & 14.8 & 0.7 & 15.3 \\
\hline
\end{tabular}


Table A1. Cont.

\begin{tabular}{|c|c|c|c|c|c|c|c|c|c|}
\hline \multirow[b]{2}{*}{ Date } & \multirow[b]{2}{*}{ Landsat ARD Product ID } & \multirow[b]{2}{*}{ Pixel Count } & \multirow[b]{2}{*}{ Area km² } & \multicolumn{5}{|c|}{ Provisional Surface Temperature ${ }^{\circ} \mathrm{C}$} & \multirow[b]{2}{*}{ USGS Streamgage ${ }^{\circ} \mathrm{C}$} \\
\hline & & & & Min & Max & Range & Mean & STD & \\
\hline $6 / 15 / 2018$ & LC08_AK_002007_20180615_20190615_C01_V01 & 74,902 & 67.4 & 1.75 & 19.45 & 17.7 & 11.5 & 2.6 & 15.4 \\
\hline $6 / 22 / 2018$ & LC08_AK_002007_20180622_20190615_C01_V01 & 11,085 & 10.0 & 10.85 & 18.45 & 7.6 & 14.3 & 0.9 & 14.2 \\
\hline $6 / 24 / 2018$ & LC08_AK_002007_20180624_20190615_C01_V01 & 99,964 & 90.0 & 10.95 & 25.85 & 14.9 & 16.2 & 1.3 & 14.5 \\
\hline $6 / 25 / 2018$ & LE07_AK_002007_20180625_20190615_C01_V01 & 12,578 & 11.3 & 12.15 & 23.55 & 11.4 & 14.8 & 1.1 & 14.9 \\
\hline $7 / 1 / 2018$ & LC08_AK_002007_20180701_20190615_C01_V01 & 23,655 & 21.3 & 11.15 & 19.95 & 8.8 & 14.7 & 1.3 & 16.5 \\
\hline $7 / 3 / 2018$ & LC08_AK_002007_20180703_20190615_C01_V01 & 86,642 & 78.0 & 0.95 & 28.75 & 27.8 & 18.4 & 1.8 & 17.3 \\
\hline $7 / 25 / 2018$ & LE07_AK_002007_20180725_20190614_C01_V01 & 121,860 & 109.7 & 13.05 & 34.65 & 21.6 & 18.3 & 1.9 & 18 \\
\hline $7 / 26 / 2018$ & LC08_AK_002007_20180726_20190614_C01_V01 & 9522 & 8.6 & 13.95 & 25.35 & 11.4 & 18.8 & 1.1 & 18.3 \\
\hline $9 / 10 / 2018$ & LC08_AK_002007_20180910_20190614_C01_V01 & 191,059 & 172.0 & 11.35 & 20.75 & 9.4 & 12.4 & 0.9 & 11.2 \\
\hline $9 / 13 / 2018$ & LE07_AK_002007_20180913_20190614_C01_V01 & 47,697 & 42.9 & 3.55 & 20.75 & 17.2 & 9.5 & 1.5 & 10.8 \\
\hline $9 / 27 / 2018$ & LE07_AK_002007_20180927_20190614_C01_V01 & 296,554 & 266.9 & 7.25 & 14.25 & 7 & 8.9 & 0.6 & 9.2 \\
\hline $9 / 29 / 2018$ & LE07_AK_002007_20180929_20190614_C01_V01 & 816 & 0.7 & -1.85 & 8.85 & 10.7 & 4.0 & 2.6 & 9 \\
\hline $5 / 9 / 2019$ & LE07_AK_002007_20190509_20190607_C01_V01 & 7839 & 7.1 & -0.55 & 18.55 & 19.1 & 5.0 & 4.8 & 1.1 \\
\hline $5 / 16 / 2019$ & ILE07_AK_002007_20190516_20190614_C01_V01 & 65,291 & 58.8 & -6.15 & 20.65 & 26.8 & 1.7 & 4.1 & 2.8 \\
\hline $5 / 18 / 2019$ & LE07_AK_002007_20190518_20190616_C01_V01 & 52,775 & 47.5 & 1.15 & 21.45 & 20.3 & 4.3 & 2.9 & 2.4 \\
\hline $5 / 19 / 2019$ & LC08_AK_002007_20190519_20190607_C01_V01 & 9802 & 8.8 & 1.15 & 23.85 & 22.7 & 7.2 & 5.3 & 3.4 \\
\hline $5 / 24 / 2019$ & LC08_AK_002007_20190524_20190607_C01_V01 & 162,233 & 146.0 & -2.55 & 22.25 & 24.8 & 7.5 & 2.8 & 7.4 \\
\hline $5 / 27 / 2019$ & LE07_AK_002007_20190527_20190625_C01_V01 & 6687 & 6.0 & 3.95 & 16.05 & 12.1 & 9.2 & 1.5 & 9.3 \\
\hline $6 / 1 / 2019$ & LE07_AK_002007_20190601_20190630_C01_V01 & 105,353 & 94.8 & 8.95 & 27.55 & 18.6 & 12.4 & 1.6 & 11.5 \\
\hline $6 / 2 / 2019$ & LC08_AK_002007_20190602_20190621_C01_V01 & 2858 & 2.6 & 7.75 & 15.55 & 7.8 & 8.6 & 0.6 & 12 \\
\hline $6 / 3 / 2019$ & LE07_AK_002007_20190603_20190701_C01_V01 & 364,838 & 328.4 & 8.25 & 23.85 & 15.6 & 12.5 & 1.1 & 12.4 \\
\hline $6 / 4 / 2019$ & LC08_AK_002007_20190604_20190621_C01_V01 & 149,252 & 134.3 & 13.85 & 27.15 & 13.3 & 15.6 & 1.5 & 12.9 \\
\hline
\end{tabular}


Table A1. Cont.

\begin{tabular}{|c|c|c|c|c|c|c|c|c|c|}
\hline \multirow[b]{2}{*}{ Date } & \multirow[b]{2}{*}{ Landsat ARD Product ID } & \multirow[b]{2}{*}{ Pixel Count } & \multirow[b]{2}{*}{ Area $\mathbf{k m}^{2}$} & \multicolumn{5}{|c|}{ Provisional Surface Temperature ${ }^{\circ} \mathrm{C}$} & \multirow[b]{2}{*}{ USGS Streamgage ${ }^{\circ}$} \\
\hline & & & & Min & Max & Range & Mean & STD & \\
\hline $6 / 9 / 2019$ & LC08_AK_002007_20190609_20190621_C01_V01 & 125,879 & 113.3 & 1.75 & 18.15 & 16.4 & 10.4 & 2.0 & 14.7 \\
\hline $6 / 11 / 2019$ & LC08_AK_002007_20190611_20190621_C01_V01 & 368,289 & 331.5 & 16.15 & 26.85 & 10.7 & 17.6 & 1.1 & 15.7 \\
\hline $6 / 12 / 2019$ & LE07_AK_002007_20190612_20190710_C01_V01 & 117,241 & 105.5 & 13.65 & 25.35 & 11.7 & 16.7 & 1.1 & 16.3 \\
\hline $6 / 17 / 2019$ & LE07_AK_002007_20190617_20190715_C01_V01 & 124,617 & 112.2 & 15.85 & 25.45 & 9.6 & 17.5 & 0.8 & 17.6 \\
\hline $6 / 18 / 2019$ & LC08_AK_002007_20190618_20190707_C01_V01 & 124,648 & 112.2 & 14.05 & 27.05 & 13 & 17.9 & 1.0 & 17.8 \\
\hline $6 / 19 / 2019$ & LE07_AK_002007_20190619_20190717_C01_V01 & 40,295 & 36.3 & 14.65 & 24.25 & 9.6 & 17.5 & 0.7 & 17.8 \\
\hline $6 / 27 / 2019$ & LC08_AK_002007_20190627_20191107_C01_V01 & 179,197 & 161.3 & 17.75 & 29.85 & 12.1 & 21.0 & 1.2 & 18.9 \\
\hline $6 / 28 / 2019$ & LE07_AK_002007_20190628_20190726_C01_V01 & 67,789 & 61.0 & 16.25 & 27.85 & 11.6 & 19.0 & 1.3 & 19.3 \\
\hline $7 / 5 / 2019$ & LE07_AK_002007_20190705_20190802_C01_V01 & 125,727 & 113.2 & 8.15 & 26.75 & 18.6 & 15.5 & 2.3 & 18.7 \\
\hline $7 / 6 / 2019$ & LC08_AK_002007_20190706_20190723_C01_V01 & 48,530 & 43.7 & 19.85 & 30.95 & 11.1 & 21.0 & 0.5 & 19.1 \\
\hline $7 / 11 / 2019$ & LC08_AK_002007_20190711_20190723_C01_V01 & 813 & 0.7 & 19.55 & 21.15 & 1.6 & 20.2 & 0.3 & 20.8 \\
\hline $7 / 14 / 2019$ & LE07_AK_002007_20190714_20190811_C01_V01 & 18,161 & 16.3 & 18.15 & 33.75 & 15.6 & 20.9 & 1.1 & 21.3 \\
\hline $7 / 22 / 2019$ & LC08_AK_002007_20190722_20190803_C01_V01 & 320 & 0.3 & 18.25 & 31.35 & 13.1 & 19.8 & 2.2 & 19 \\
\hline $7 / 27 / 2019$ & ILC08_AK_002007_20190727_20190803_C01_V01 & 1451 & 1.3 & 12.15 & 19.35 & 7.2 & 16.7 & 0.9 & 17.5 \\
\hline $7 / 28 / 2019$ & LE07_AK_002007_20190728_20190825_C01_V01 & 13,261 & 11.9 & 14.35 & 28.45 & 14.1 & 18.7 & 2.0 & 17.7 \\
\hline $7 / 29 / 2019$ & LC08_AK_002007_20190729_20190807_C01_V01 & 179 & 0.2 & 16.35 & 20.25 & 3.9 & 18.0 & 0.9 & 17.7 \\
\hline $7 / 30 / 2019$ & LE07_AK_002007_20190730_20191107_C01_V01 & 589 & 0.5 & 12.85 & 22.25 & 9.4 & 16.1 & 1.7 & 17.4 \\
\hline $8 / 20 / 2019$ & LE07_AK_002007_20190820_20190917_C01_V01 & 2367 & 2.1 & 13.05 & 20.25 & 7.2 & 15.5 & 1.3 & 15.1 \\
\hline $8 / 21 / 2019$ & LC08_AK_002007_20190821_20190905_C01_V01 & 326,119 & 293.5 & 11.35 & 28.25 & 16.9 & 16.6 & 1.1 & 15 \\
\hline $8 / 22 / 2019$ & LE07_AK_002007_20190822_20190920_C01_V01 & 149,011 & 134.1 & 11.85 & 24.05 & 12.2 & 14.6 & 0.8 & 15.1 \\
\hline $8 / 23 / 2019$ & LC08_AK_002007_20190823_20190905_C01_V01 & 51,403 & 46.3 & 14.75 & 22.65 & 7.9 & 15.8 & 0.5 & 15 \\
\hline $8 / 29 / 2019$ & LE07_AK_002007_20190829_20190925_C01_V01 & 29,596 & 26.6 & 11.25 & 22.65 & 11.4 & 14.3 & 1.2 & 13.7 \\
\hline
\end{tabular}


Table A1. Cont.

\begin{tabular}{|c|c|c|c|c|c|c|c|c|c|}
\hline \multirow[b]{2}{*}{ Date } & \multirow[b]{2}{*}{ Landsat ARD Product ID } & \multirow[b]{2}{*}{ Pixel Count } & \multirow[b]{2}{*}{ Area $\mathbf{k m}^{2}$} & \multicolumn{5}{|c|}{ Provisional Surface Temperature ${ }^{\circ} \mathrm{C}$} & \multirow[b]{2}{*}{ USGS Streamgage ${ }^{\circ}$} \\
\hline & & & & Min & Max & Range & Mean & STD & \\
\hline $8 / 30 / 2019$ & LC08_AK_002007_20190830_20190919_C01_V01 & 57,534 & 51.8 & 11.05 & 22.55 & 11.5 & 14.2 & 0.8 & 13.4 \\
\hline $9 / 16 / 2019$ & LE07_AK_002007_20190916_20191029_C01_V01 & 19,686 & 17.7 & 9.65 & 19.35 & 9.7 & 12.1 & 1.2 & 11.8 \\
\hline $9 / 30 / 2019$ & LE07_AK_002007_20190930_20191029_C01_V01 & 118,707 & 106.8 & 1.55 & 15.75 & 14.2 & 7.7 & 1.2 & 7.7 \\
\hline $10 / 1 / 2019$ & LC08_AK_002007_20191001_20191020_C01_V01 & 77,949 & 70.2 & 6.05 & 12.35 & 6.3 & 7.9 & 0.8 & 7.7 \\
\hline $10 / 8 / 2019$ & LC08_AK_002007_20191008_20191022_C01_V01 & 111,841 & 100.7 & 1.05 & 10.35 & 9.3 & 6.3 & 1.0 & 6.7 \\
\hline $5 / 4 / 2020$ & LE07_AK_002007_20200504_20200602_C01_V01 & 33,566 & 30.2 & -4.55 & 22.75 & 27.3 & 6 & 4.4 & 0.2 \\
\hline $5 / 5 / 2020$ & LC08_AK_002007_20200505_20200511_C01_V01 & 5981 & 5.4 & 2.95 & 25.05 & 22.1 & 11.6 & 4.5 & 0.1 \\
\hline $5 / 11 / 2020$ & LE07_AK_002007_20200511_20200610_C01_V01 & 14,893 & 13.4 & -2.25 & 17.55 & 19.8 & 3.6 & 4.1 & 0.3 \\
\hline $5 / 13 / 2020$ & LE07_AK_002007_20200513_20200611_C01_V01 & 2605 & 2.3 & -1.25 & 19.85 & 21.1 & 3.8 & 3.2 & 0.3 \\
\hline $5 / 18 / 2020$ & LE07_AK_002007_20200518_20200616_C01_V01 & 152,125 & 136.9 & 0.55 & 20.15 & 19.6 & 5.1 & 3.1 & 3.6 \\
\hline $5 / 19 / 2020$ & LC08_AK_002007_20200519_20200528_C01_V01 & 486,893 & 438.2 & 3.65 & 27.85 & 24.2 & 10.4 & 3.4 & 4.9 \\
\hline $5 / 27 / 2020$ & LE07_AK_002007_20200527_20200627_C01_V01 & 40,258 & 36.2 & 6.15 & 14.85 & 8.7 & 9.2 & 1.1 & 8.4 \\
\hline $5 / 28 / 2020$ & LC08_AK_002007_20200528_20200610_C01_V01 & 396,327 & 356.7 & 10.45 & 22.15 & 11.7 & 12.4 & 1.8 & 8.9 \\
\hline $5 / 29 / 2020$ & ILE07_AK_002007_20200529_20200627_C01_V01 & 87,418 & 78.7 & 2.45 & 21.95 & 19.5 & 9.9 & 2.8 & 9.7 \\
\hline $6 / 3 / 2020$ & LE07_AK_002007_20200603_20200702_C01_V01 & 2107 & 1.9 & 12.75 & 20.15 & 7.4 & 14 & 0.9 & 13.3 \\
\hline $6 / 11 / 2020$ & LC08_AK_002007_20200611_20200627_C01_V01 & 20,617 & 18.6 & 4.05 & 21.65 & 17.6 & 13.5 & 2.1 & 14.7 \\
\hline $6 / 13 / 2020$ & LC08_AK_002007_20200613_20200627_C01_V01 & 122,783 & 110.5 & -9.65 & 25.35 & 35 & 18.1 & 1.3 & 15.1 \\
\hline $6 / 19 / 2020$ & LE07_AK_002007_20200619_20200719_C01_V01 & 10,522 & 9.5 & 6.45 & 18.05 & 11.6 & 12.6 & 1.8 & 16.8 \\
\hline $6 / 20 / 2020$ & LC08_AK_002007_20200620_20200709_C01_V01 & 138,362 & 124.5 & 7.95 & 23.75 & 15.8 & 18.6 & 0.7 & 17.2 \\
\hline $6 / 29 / 2020$ & LC08_AK_002007_20200629_20200709_C01_V01 & 31,806 & 28.6 & 4.45 & 19.25 & 14.8 & 15.1 & 1.4 & 15.5 \\
\hline $7 / 13 / 2020$ & LC08_AK_002007_20200713_20200724_C01_V01 & 151,828 & 136.6 & 0.35 & 26.35 & 26 & 15.2 & 2.5 & 16.4 \\
\hline $7 / 14 / 2020$ & LE07_AK_002007_20200714_20200825_C01_V01 & 98,874 & 89 & 6.45 & 20.75 & 14.3 & 14.4 & 1.9 & 16.8 \\
\hline
\end{tabular}


Table A1. Cont.

\begin{tabular}{|c|c|c|c|c|c|c|c|c|c|}
\hline \multirow[b]{2}{*}{ Date } & \multirow[b]{2}{*}{ Landsat ARD Product ID } & \multirow[b]{2}{*}{ Pixel Count } & \multirow[b]{2}{*}{ Area km $^{2}$} & \multicolumn{5}{|c|}{ Provisional Surface Temperature ${ }^{\circ} \mathrm{C}$} & \multirow[b]{2}{*}{ USGS Streamgage ${ }^{\circ} \mathrm{C}$} \\
\hline & & & & Min & Max & Range & Mean & STD & \\
\hline $7 / 15 / 2020$ & LC08_AK_002007_20200715_20200724_C01_V01 & 156,005 & 140.4 & 14.75 & 26.75 & 12 & 19 & 0.9 & 17.2 \\
\hline $7 / 23 / 2020$ & LE07_AK_002007_20200723_20200821_C01_V01 & 203,325 & 183 & 14.55 & 27.25 & 12.7 & 18 & 1.1 & 17 \\
\hline $8 / 1 / 2020$ & LE07_AK_002007_20200801_20200830_C01_V01 & 71,341 & 64.2 & 14.95 & 28.05 & 13.1 & 17.9 & 1.2 & 16 \\
\hline $8 / 8 / 2020$ & LE07_AK_002007_20200808_20200908_C01_V01 & 13,052 & 11.7 & 11.35 & 18.55 & 7.2 & 15.4 & 0.8 & 15.9 \\
\hline $8 / 14 / 2020$ & LC08_AK_002007_20200814_20200825_C01_V01 & 96,735 & 87.1 & 8.65 & 22.25 & 13.6 & 17.5 & 0.9 & 16.5 \\
\hline $8 / 16 / 2020$ & LC08_AK_002007_20200816_20200825_C01_V01 & 301,987 & 271.8 & 16.55 & 26.95 & 10.4 & 17.8 & 0.6 & 16.3 \\
\hline $8 / 17 / 2020$ & LE07_AK_002007_20200817_20200915_C01_V01 & 116,432 & 104.8 & 16.05 & 28.95 & 12.9 & 17.6 & 0.8 & 16.7 \\
\hline $8 / 25 / 2020$ & LC08_AK_002007_20200825_20200907_C01_V01 & 2390 & 2.2 & 13.45 & 20.75 & 7.3 & 16.3 & 0.9 & 16 \\
\hline $9 / 2 / 2020$ & LE07_AK_002007_20200902_20201001_C01_V01 & 1223 & 1.1 & 5.15 & 11.25 & 6.1 & 9.1 & 0.9 & 14.5 \\
\hline $9 / 9 / 2020$ & LE07_AK_002007_20200909_20201022_C01_V01 & 38,321 & 34.5 & 8.55 & 15.05 & 6.5 & 11.9 & 0.7 & 14.2 \\
\hline $9 / 10 / 2020$ & LC08_AK_002007_20200910_20200921_C01_V01 & 27,288 & 24.6 & 9.95 & 16.65 & 6.7 & 12.1 & 0.7 & 14 \\
\hline $9 / 24 / 2020$ & LC08_AK_002007_20200924_20201016_C01_V01 & 285,961 & 257.4 & 2.25 & 12.45 & 10.2 & 9.1 & 1.1 & 11.7 \\
\hline $9 / 25 / 2020$ & LE07_AK_002007_20200925_20201024_C01_V01 & 44,529 & 40.1 & 0.55 & 6.75 & 6.2 & 2.9 & 0.9 & 8.7 \\
\hline $9 / 26 / 2020$ & LC08_AK_002007_20200926_20201022_C01_V01 & 83,683 & 75.3 & 1.55 & 9.55 & 8 & 5.5 & 1.2 & 8.1 \\
\hline $10 / 10 / 2020$ & LC08_AK_002007_20201010_20201022_C01_V01 & 39,303 & 35.4 & 3.15 & 10.35 & 7.2 & 6.4 & 1 & 7.7 \\
\hline
\end{tabular}




\section{References}

1. Reid, G.K. Ecology of Inland Waters and Estuaries; Reinhold Publishing Co.: New York, NY, USA, 1961.

2. Macan, T.T. Freshwater Ecology, 2nd ed.; Longmn Group: London, UK, 1974.

3. Yang, D.; Marsh, P.; Ge, S. Heat flux calculations for Mackenzie and Yukon Rivers. Polar Sci. 2014, 8, 232-241. [CrossRef]

4. Kanevskiy, M.; Shur, Y.; Krzewinski, T.; Dillon, M. Structure and properties of ice-rich permafrost near Anchorage, Alaska. Cold Reg. Sci. Technol. 2013, 93,1-11. [CrossRef]

5. Williams, J.R. Observations of Freeze-Up and Break-Up of the Yukon River at Beaver Alaska. J. Glaciol. 1955, 2, 488-495. [CrossRef]

6. Halm, D.R.; Dornblaser, M.M. Water and Sediment Quality in the Yukon River and Its Tributaries between Atlin, British Columbia, Canada, and Eagle, Alaska, USA, 2004; U.S. Geological Survey: Reston, VA, USA, 2007; p. 120.

7. Zimmerman, C.E.; Finn, J.E. A simple method for in situ monitoring of water temperature in substrates used by spawning salmonids. J. Fish Wildl. Manag. 2012, 3, 288-295. [CrossRef]

8. National Research Council Upstream: Salmon and Society in the Pacific Northwest; The National Academies Press: Washington, DC, USA, 1996.

9. Armour, C.L. Guidance for Evaluating and Recommending Temperature Regimes to Protect Fish; U.S. Fish and Wildlife Service: Washington, DC, USA, 1991; p. 13.

10. von Biela, V.R.; Bowen, L.; McCormick, S.D.; Carey, M.P.; Donnelly, D.S.; Waters, S.; Regish, A.M.; Laske, S.M.; Brown, R.J.; Larson, S.; et al. Evidence of prevalent heat stress in Yukon River Chinook salmon. Can. J. Fish. Aquat. Sci. 2020, 77, 1878-1892. [CrossRef]

11. Hari, R.E.; Livingstone, D.M.; Siber, R.; Burkhardt-Holm, P.; Guttinger, H. Consequences of climatic change for water temperature and brown trout populations in Alpine rivers and streams. Glob. Change Biol. 2006, 12, 10-26. [CrossRef]

12. U.S. Geological Survey. USGS Water Data for the Nation: National Water Information System Database. Available online: https://waterdata.usgs.gov/nwis (accessed on 22 January 2021).

13. Pavelsky, T.H.; Allen, G.H.; Miller, Z.F. Spatial Patterns of River Width in the Yukon River Basin. In Remote Sensing of the Terrestrial Water Cycle; Geophysical Monograph 206; John Wiley \& Sons, Inc.: Washington, DC, USA, 2015; pp. $131-141$.

14. Yang, D.; Petersen, A. River Water Temperature in Relation to Local Air Temperature in the Mackenzie and Yukon Basins. Arctic 2017, 70, 47-58. [CrossRef]

15. Handcock, R.N.; Torgersen, C.E.; Cherkauer, K.A.; Gillespie, A.R.; Tockner, K.; Faux, R.N.; Tan, J. Thermal Infrared Remote Sensing of Water Temperature in Riverine Landscapes. In Fluvial Remote Sensing for Science and Management; John Wiley \& Sons, Ltd.: Washington, DC, USA, 2012; pp. 85-113.

16. Campbell, J.B.; Wynne, R.H. Introduction to Remote Sensing, 5th ed.; The Guilford Press: New York, NY, USA, 2011; ISBN 1-60918-176-X.

17. Torgersen, C.E.; Faux, R.N.; McIntosh, B.A.; Poage, N.J.; Norton, D.J. Airborne Thermal Remote Sensing for Water Temperature Assessment in Rivers and Streams. Remote Sens. Environ. 2001, 76, 386-398. [CrossRef]

18. Handcock, R.N.; Gillespie, A.R.; Cherkauer, K.A.; Kay, J.E.; Burges, S.J.; Kampf, S.K. Accuracy and uncertainty of thermal-infrared remote sensing of stream temperatures at multiple spatial scales. Remote Sens. Environ. 2006, 100, 427-440. [CrossRef]

19. Chikita, K.A.; Kemnitz, R.; Kumai, R. Characteristics of sediment discharge in the subarctic Yukon River, Alaska. CATENA 2002, 48, 235-253. [CrossRef]

20. Landsat_Earth Observation Satellites; U.S. Department of the Interior U.S. Geological Survey: Washington, DC, USA, 2020; pp. 1-4.

21. Hagan, J.A. Assessing the AccuracyofLandsat-Derived Stream Temperature for use in Juvenile Salmond Habitat Assessments on the Anchor River, Alaska. Master's Thesis, Alaska Pacific University, Anchorage, AK, USA, 2017.

22. U.S. Landsat Analysis Ready Data (ARD). Available online: https://www.usgs.gov/core-science-systems/nli/landsat/uslandsat-analysis-ready-data?qt-science_support_page_related_con=0\#qt-science_support_page_related_con (accessed on 15 July 2020).

23. Dwyer, J.L.; Roy, D.P.; Sauer, B.; Jenkerson, C.B.; Zhang, H.K.; Lymburner, L. Analysis Ready Data: Enabling Analysis of the Landsat Archive. Remote Sens. 2018, 10, 1363. [CrossRef]

24. USGS/EROS. U.S. Landsat Collection 1 Analysis Ready Data (ARD) Data Format Control Book; EROS: Sioux Falls, SD, USA, 2019.

25. Cook, M.J.; Schott, J.R.; Mandel, J.; Raqueno, N. Development of an operational calibration methodology for the Landsat thermal data archive and initial testing of the atmospheric compensation component of a Land Surface Temperature (LST) Product from the archive. Remote Sens. 2014, 6, 11244-11266. [CrossRef]

26. USGS/EROS. Landsat Surface Temperature (ST) Product Guide; EROS: Sioux Falls, SD, USA, 2018; pp. 1-26.

27. Jimenez-Munoz, J.C.; Cristobal, J.; Sobrino, J.A.; Soria, G.; Ninyerola, M.; Pons, X. Revision of the Single-Channel Algorithm for Land Surface Temperature Retrieval From Landsat Thermal-Infrared Data. IEEE Trans. Geosci. Remote Sens. 2009, 47, 339-349. [CrossRef]

28. Hulley, G.C.; Hughes, C.G.; Hook, S.J. Quantifying uncertainties in land surface temperature and emissivity retrievals from ASTER and MODIS thermal infrared data. J. Geophys. Res. Atmos. 2012, 117. [CrossRef]

29. Cook, M.J. Atmospheric Compensation for a Landsat Land Surface Temperature Product. Ph.D. Dissertation, Rochester Institute of Technology, Rochester, NY, USA, 2014. 
30. Cook, M.J.; Schott, J.R. Atmospheric Compensation for a Landsat Land Surface Temperature Product 2014. Presented at the Landsat Science Team Meeting, Corvallis, OR, USA, 22-24 July 2014.

31. Serreze, M.C.; Barry, R.G. Processes and impacts of Arctic amplification: A research synthesis. Glob. Planet. Change 2011, 77, 85-96. [CrossRef]

32. Brabets, T.P.; Wang, B.; Meade, R.H. Environmental and Hydrologic Overview of the Yukon River Basin, Alaska and Canada; U.S. Department of the Interior U.S. Geological Survey: Anchorage, Alaska, 2000; p. 114.

33. Camill, P. Permafrost Thaw Accelerates in Boreal Peatlands During Late-20th Century Climate Warming. Clim. Change 2005, 68, 135-152. [CrossRef]

34. Larsen, C.F.; Burgess, E.; Arendt, A.A.; O’Neel, S.; Johnson, A.J.; Kienholz, C. Surface melt dominates Alaska glacier mass balance Geophys. Res. Lett. 2015, 42, 5902-5908. [CrossRef]

35. Euskirchen, E.S.; Bennett, A.; Breen, A.L.; Genet, H.; Lindgren, M.A.; Kurkowski, T.A.; McGuire, A.D.; Rupp, T.S. Consequences of changes in vegetation and snow cover for climate feedbacks in Alaska and northwest Canada. Environ. Res. Lett. 2016, 11, 105003. [CrossRef]

36. Nowacki, G.J.; Spencer, P.; Fleming, M.; Brock, T.; Jorgenson, T. Unified Ecoregions of Alaska: 2001; Open-File Report; Geological Survey (U.S.): Reston, VA, USA, 2003.

37. ArcGIS Desktop 10.8.1; Environmental Systems Research Institute: Redlands, CA, USA, 2021.

38. ESRI Imagery [Basemap]. Esri, Maxar, Earthstar Geographics, USDA FSA, USGS, Aerogrid, IGN, IGP, and the GIS User Community. 2020. Available online: https://services.arcgisonline.com/ArcGIS/rest/services/World_Imagery/MapServer (accessed on 15 July 2020).

39. ESRI “USA Topo Map” [Basemap]. Copyright: @ 2021 National Geographic Society, i-Cubed. Available online: https://services. arcgisonline.com/ArcGIS/rest/services/USA_Topo_Maps/MapServer (accessed on 15 July 2020).

40. Landsat 7 (L7) Data Users Handbook; U.S. Department of the Interior U.S. Geological Survey, EROS: Sioux Falls, SD, USA, 2019; p. 139.

41. Laraby, K.G.; Schott, J.R. Uncertainty estimation method and Landsat 7 global validation for theLandsat surface temperature product. Remote Sens. Environ. 2018, 216, 472-481. [CrossRef] 